Departamento de Historia

Universidad de Santiago de Chile

Revista de Historia Social

y de las Mentalidades

Volumen 25, $\mathrm{N}^{\circ} 1,2021: 111-152$

Issn Online: 0719-4749

\title{
EN BUSCA DEL EQUILIBRIO. LAS COMISIONES REVISORAS DE LEYES ADUANERAS EN ARGENTINA, 1894-1907*
}

\author{
LOOKING FOR BALANCE. CUSTOMS LAW REVIEW \\ COMMISSIONS IN ARGENTINA, 1894-1907
}

\author{
DRA. AGUSTINA RAYES** \\ CEHP-UNSAM/CONICET \\ Buenos Aires, Argentina \\ Email: arayes@unsam.edu.ar / agusrayes@hotmail.com \\ Id-ORCID: 0000-0002-5335-0675
}

\begin{abstract}
En 1894, 1899 y 1907, en Argentina, se formaron
Comisiones Revisoras de las leyes aduaneras para realizar estudios sobre el nivel arancelario y la Tarifa de Avalúos (valores oficiales sobre los que se aplicaban los gravámenes de exportación e importación). Constituidas a propuesta del Poder Ejecutivo para informar en los debates parlamentarios sobre la materia, fueron un reflejo de la política comercial del período. Nuestra investigación está basada en leyes aduaneras,
\end{abstract}

\begin{abstract}
In 1894, 1899, and 1907, in Argentina, Customs Laws Review Commissions were formed to carry out studies on the tariff level and the Tarifa de Avalúos (official values applied on export and import taxes). Constituted at the proposal of the Executive Power to inform parliamentary debates on the subject, they were a reflection of the trade policy during the period. Our research is based on customs laws, trade statistics,
\end{abstract}

* $\quad$ Recibido: 2 de Diciembre del 2020; Aceptado: 23 de Marzo del 2021.

** El presente artículo forma parte del plan de trabajo principal que la autora realiza como parte de su desempeño en el Consejo Nacional de Investigaciones Científicas y Técnicas de Argentina y ha sido uno de los temas estudiados en el PICT2016-1912 a su cargo.

Este trabajo recibió financiamiento del PICT 2016-1912. Las versiones previas fueron presentadas en las VII Jornadas de Historia de la Industria y los Servicios de la Universidad de Buenos Aires y en el Seminario Interno de Investigación de la Escuela de Política y Gobierno de la Universidad Nacional de San Martín. La autora agradece los comentarios de los y las participantes de esas instancias, así como las lecturas de la investigación y las observaciones sobre el tema de Ángel Cerra, Alfonso Dingemans, Roy Hora, Leandro Losada, Carla Rivera, Fernando Rocchi, Marcela Sabaté y José María Serrano Sanz, y las evaluaciones de dos árbitros anónimos. Desde luego, la autora asume absoluta responsabilidad por las ideas aquí vertidas. 
estadísticas comerciales y, especialmente, debates e informes de las Comisiones Revisoras. Iniciamos con el papel de estos cuerpos en la dinámica de la política arancelaria argentina de la época. Luego, se aborda, por un lado, su composición y la participación de actores externos, y, por el otro, los principales temas planteados. Finalmente, analizamos en qué medida fueron consideradas las proposiciones en las leyes aduaneras posteriores.

Palabras clave: política arancelaria; leyes aduaneras; economía agroexportadora; Argentina and discussions and reports of the Review Commissions. We begin with the role of these corps in the dynamics of Argentine tariff policy at the time. Then, we study, on the one hand, their composition and the participation of external actors, and, on the other, the main topics pointed out. Finally, we analyze to what extent the propositions in the subsequent customs laws were considered.

Keywords: Tariff policy; Customs Laws; Agroexport Economy; Argentina

Cómo citar: Rayes, Agustina. (2021). "En busca del equilibrio. Las Comisiones Revisoras de Leyes Aduaneras en Argentina, 1894-1907". Revista Historia Social y de las Mentalidades, 25(1), 111-152. https://doi.org/10.35588/rhsm.v25i1.4712

\section{INTRODUCCIÓN}

Entre las últimas tres décadas del siglo XIX y la víspera de la Primera Guerra Mundial, Argentina fue uno de los países que más creció en el mundo (Bolt, et al.). Una buena parte de su crecimiento se debió a la expansión del sector exportador y a la llegada de importaciones, algunas de las cuales contribuyeron parcialmente a la diversificación de la economía nacional. Durante este período, con fluctuaciones, el comercio exterior aportó aproximadamente la mitad del Producto Bruto Interno (Gerchunoff y Llach 487). Dada la trascendencia del sector, la política comercial en general, y la arancelaria en particular, naturalmente fueron aspectos relevantes no solo para los contemporáneos sino también para los estudios historiográficos posteriores que se hicieron sobre el tema. Dependiendo del enfoque, la literatura ha caracterizado la posición argentina sobre los gravámenes al intercambio externo como liberal, proteccionista o fiscalista. ${ }^{1}$ Las conclusiones, generalmente categóricas sobre la materia, contrastan en la mayoría de los abordajes con la ausencia de análisis pormenorizados, sistemáticos y basados en evidencia empírica suficiente o en datos seriados y fiables.

En este sentido, este artículo no zanja el debate acerca de la naturaleza de la política arancelaria durante la economía agro-exportadora, sino que aporta elementos para pensar sobre la complejidad del problema al estudiar las,

1 Para una revisión de la literatura, véase, entre otros, Rocchi; Hora; Regalsky. 
escasamente abordadas por la historiografía, Comisiones Revisoras de las leyes aduaneras que tuvieron lugar en 1894, 1899 y 1907 (en adelante, CR-1894, CR1899 y CR-1907). Las mismas constituyeron espacios de discusión ampliada y detallada de los aranceles y de los aforos sobre los que se basó la carga impositiva. $\mathrm{Su}$ variada composición y la diversidad de posiciones reflejan el delicado equilibrio existente entre sectores, actores y temas involucrados. Asimismo, su funcionamiento revela que algunas medidas atribuidas generalmente a la primacía de determinados intereses, como la desactualización de los valores oficiales, no se debieron sino a las restricciones materiales y humanas propias de un aparato estatal todavía en construcción.

Nuestra investigación se basa en leyes aduaneras, estadísticas comerciales $\mathrm{y}$, especialmente, debates e informes de las Comisiones Revisoras. Iniciamos con una explicación sobre el papel de estos cuerpos en la dinámica de la política arancelaria argentina de la época. Luego, abordamos, por un lado, su composición y la participación de actores externos, y, por el otro, los principales temas planteados. Finalmente, analizamos en qué medida fueron consideradas las conclusiones aportadas en las leyes aduaneras posteriores.

\section{LAS COMISIONES REVISORAS EN LA DINÁMICA DE LA POLÍTICA ARANCELARIA}

La Constitución de 1853 preveía que parte de los fondos del Tesoro Nacional se extrajera de los derechos al comercio exterior (artículo 4), así como consideraba que, entre las atribuciones del Congreso, estaban las de legislar en materia aduanera (artículo 17 y artículo 64-inciso 1) y promover la industria (artículo 64-inciso 16). En este marco, proliferaron las leyes de Aduanas desde 1862, dando cuenta del proceso de construcción del Estado-Nación.

Los derechos aduaneros fueron el principal instrumento de la política comercial durante la economía agro-exportadora. Su alcance y aplicación fue precisada no solo en las leyes aduaneras regulares, sino también en disposiciones especiales, en decretos y en informes o resoluciones gubernamentales. A priori no hubo ningún elemento visible de prohibición al comercio durante el período estudiado, es decir, hasta donde conocemos, no se impusieron cuotas ni barreras para-arancelarias a la entrada o salida de las mercancías. En este sentido, la operatoria para el intercambio mercantil fue más o menos estandarizada. Los productos exportados o importados se valoraron en relación a un avalúo oficial. Si un artículo, que ingresaba o salía por la Aduana argentina, tenía que pagar gravámenes, estos últimos estaban vinculados a la valuación que las 
leyes aduaneras les otorgaban (si el producto no estaba en la lista (Tarifa de Avalúos) se pagaba según la declaración de valor, a menos que estuviese exento de gravámenes). En consecuencia, para conocer el nivel de protección no es suficiente con observar los impuestos (ad valorem o específicos) $)^{2}$ sino también las valoraciones de cada bien o grupo de bienes. Técnicamente, se asumía que el valor oficial de un bien se correspondía al "valor real", es decir, al precio de mercado y, por ello, los valores oficiales fueron presentados en los registros estadísticos como "valores de aforo" (ad-forum significa "en el mercado"). Se suponía que los valores oficiales cambiaban periódicamente, dado que era más sencillo para las autoridades controlar los aforos que modificar las escalas de los aranceles aduaneros. Sin embargo, recientemente se ha probado que la actualización de la Tarifa de Avalúos fue más bien esporádica y que a distintos tipos de bienes se les asignaba el mismo valor por varios años continuados (Rayes, Castro e Ibarra), de manera que, tal como sostuviera parte de la literatura previa, el arancel efectivo pudo estar por encima o por debajo del arancel nominal (Cortés Conde, "Argentina" 387; Hora, "La política económica"). Dentro de esta trama, veamos qué papel jugaron las Comisiones Revisoras de las Leyes Aduaneras y por qué constituyen una prueba de la dificultad de concluir rápidamente acerca de la dirección de la política arancelaria.

Como señalamos, la materia aduanera era atribución del Poder Legislativo; en la práctica, el Congreso sancionaba las leyes, detallando qué artículos quedaban libres de impuestos y cuáles, y en qué medida, pagaban. No obstante, los derechos aduaneros se basaban en avalúos, reglados por el Poder Ejecutivo, que durante los años en estudio estuvo en manos del Partido Autonomista Nacional (PAN). Al igual que ocurría con los Ministerios de Agricultura y del Interior, desde donde se mantuvieron negociaciones continuas con intereses organizados y agentes sociales, el Ministerio de Hacienda procuró dialogar con diversos actores a fin de conocer los efectos de las leyes aduaneras y para ello conformó las Comisiones Revisoras en tres oportunidades: 1894, 1899 y 1907 (González Bollo 108-111). En efecto, esta medida puede encuadrarse dentro de la pretensión del partido oficialista de canalizar diversos temas conflictivos por vías institucionales para desactivar la movilización popular (Cucchi y Rojkind).

Avanzada la década de 1890, en el gobierno surgió la necesidad de estudiar los niveles arancelarios, así como de examinar los valores oficiales sobre los que se aplicaban, debido, entre otras cuestiones, a las transformaciones

2 El tipo de arancel a pagar dependía del producto. Los artículos pagaron mayormente derechos ad valorem, aunque progresivamente desde la década de 1890 se extendió el uso de derechos específicos, en especial para bienes de consumo importados, como alimentos, bebidas o tabaco. 
que el país experimentaba en su estructura productiva, a la diversificación de actores e intereses sociales y económicos, a los problemas de financiamiento del estado central, al encarecimiento del costo de vida y al deterioro de los términos de intercambio. Se trataba, después de todo, de un quinquenio agitado, caracterizado por creciente actividad cívica y mayor participación política (Gallo, "Un quinquenio"). Por decreto del 13 de enero de 1894, el Poder Ejecutivo, a cargo de Luis Sáenz Peña, sancionó la designación de una comisión ad hoc destinada a estudiar cuestiones arancelarias y hacer recomendaciones al Congreso para reformar la ley aduanera. Así, nació la CR-1894, la primera en su naturaleza. Su labor fue inicialmente presentada como la oportunidad de que el Poder Legislativo cuente con información para dictaminar no solo sobre los aranceles sino también sobre los aforos y que, a partir de entonces, se encargue de modificar (actualizar) lo que fuera necesario (CR-1894, Acta No 8). Finalmente, el 20 de septiembre de 1894 la CR-1894 envió sus informes al Ministro de Hacienda, José Terry. Se trataba del primer estudio de estas características y el presidente de la Comisión expresaba sobre el mismo: "con todas sus deficiencias la investigación practicada es el primer sumario administrativo que se instruye, a los cuarenta años de vida regular, en el proceso de la renta pública, cuyos nueve décimos entraban por Aduana (...) Es un primer paso, un mero ensayo, una simple orientación de rumbos definidos" (Carta del Presidente de CR-1894).

Por ser la primera, la CR-1894 tuvo más funciones que sus sucesoras (Carta de la CR-1894), dejó los registros más detallados de su labor, y sentó el precedente para las Comisiones Revisoras que se organizaron en 1899 y en 1907. En general, los objetivos de todas ellas fueron, por un lado, conocer la opinión de los diversos actores socio-económicos en materia aduanera, $\mathrm{y}$, por el otro, saber cuánto influían los aranceles sobre el sector primario, el comercio, la industria, el consumo, las relaciones internacionales y la renta del país. Las expectativas comunes a todas fueron que sus investigaciones sirvieran para evitar el contrabando, atenuar o frenar la caída de la inmigración, enfrentar el encarecimiento de la vida e impedir represalias por parte de los socios comerciales. En síntesis, las Comisiones Revisoras tuvieron la difícil tarea de conciliar las exigencias de la producción interna con el abaratamiento del consumo y las necesidades del Tesoro Nacional, lo que explica los intensos debates entre sus miembros y los actores que presentaron sus posturas, todo lo cual quedó registrado en actas ordenadas por grupo de productos o temario (despachos presentados por las subcomisiones), y editadas y publicadas en informes póstumos, fuentes principales de nuestra investigación.

Todas las Comisiones Revisoras tuvieron las tareas de estudiar en qué medida cada uno de los derechos ad valorem y específicos debían mantenerse o 
modificarse. También debían analizar la posibilidad de eliminar o disminuir los aranceles sobre artículos de primera necesidad, y si los materiales dirigidos al fomento de la industria local debían ingresar exentos de impuestos o con aranceles bajos, a fin de no vulnerar el principio de igualdad fiscal en las cargas públicas. Para empezar sus trabajos, las Comisiones Revisoras enviaron cartas a todas las entidades comerciales y empresariales a fin de solicitar información sobre sus respectivos rubros, dada la ausencia de estadísticas seriadas sobre distintas actividades económicas. Asimismo, publicaron avisos en periódicos alentando a los productores y consumidores a prestar su parecer, en exposiciones orales o por escrito. En todos los casos, los reclamos llegaron masivamente, aunque se sabía que muchos agentes económicos desconfiaban de participar porque descreían de la real capacidad de estos cuerpos para promover transformaciones.

La CR-1894 tuvo treinta laboriosas sesiones, de las que diez estuvieron dedicadas a los azúcares y los vinos, lo que es esperable dada la centralidad de estos sectores en los debates de la época sobre la viabilidad del proteccionismo y sus efectos en economías del Interior. La CR-1894 se encargó del estudio parcial de los aforos y los derechos aduaneros. Ello implicó, primero, investigar el aforo asignable a 3.861 partidas para establecer el valor real de las mercaderías en depósito (es decir, el precio en el punto de embarque más fletes, más seguros, más comisiones, etc., hasta el puerto de Buenos Aires, el que concentraba por entonces más del 80\% del valor total importado (Vázquez Presedo 68-69)). Segundo, uniformar los artículos de la misma especie, dispersos en toda la tarifa con diversos gravámenes. Tercero, corregir los errores e incongruencias que incitaban el contrabando -dado que se dejaban libres cada vez más artículos que debían gravarse mientras otros bienes pagaban gravámenes muy onerosos-; también se buscaba evitar tramitaciones largas y engorrosas para el servicio público, así como la acumulación de sumarios y expedientes. La idea era que casi todos los productos paguen algo, liberando únicamente lo que quedaba expresamente asentado. También se buscaba anular el derecho adicional del 1\% - establecido en 1890 por la pérdida de ingresos debido al cobro de derechos a la importación en pesos moneda nacional (depreciados en relación a los pesos oro) y las urgencias financieras estatales que inauguraron la década (Ley del Presupuesto General de la República Argentina para el ejercicio de 1890, art.3). ${ }^{3}$

Luego de la reforma aduanera, el Congreso resolvió que la secretaría de la CR-1894 continuase recogiendo datos a fin de mantener la información

3 La misma fue replicada por la Ley del Presupuesto General de la República Argentina para el ejercicio de 1891. 
actualizada, pero cambios ministeriales, no precisados en las fuentes, lo impidieron. Es probable que los costos materiales y humanos impidieran llevar adelante las tareas de actualización en un estado en construcción, ${ }^{4}$ con apremios fiscales más allá de que mejorara la performance económica de la segunda mitad de la última década decimonónica en relación a los años previos (Gerchunoff y Llach 487). En efecto, se abandonó el estudio sistemático de precios y, por lo tanto, cinco años más tarde hubo que retomar la tarea.

Nuevamente, un contexto de encarecimiento del costo de vida y de disminución de la inmigración (algunos indicadores en Ferreres) alentó la revisión arancelaria desde el gobierno conservador. Así, por decreto, el Poder Ejecutivo - liderado en esta oportunidad por Julio Argentino Roca- creó otra Comisión Revisora encargada de estudiar el arancel para 1900. La CR1899 reportó sus conclusiones a principios de 1900, enfatizando que, en todo momento, procuró consultar las conveniencias de los consumidores y de la renta $\mathrm{y}$ que, de acuerdo a las reiteradas reuniones que sus miembros tuvieron con representantes del comercio y de la industria, el principal problema continuaban siendo los "malos avalúos" (Carta del Presidente de la CR-1899). Ello significa que el mayor inconveniente para evaluar el grado de proteccionismo estaba en los precios oficiales sobre los que se aplicaban los aranceles ad valorem o específicos, los que, a juicio de distintos actores involucrados en cada rubro, no reflejaban los movimientos de mercado, estando infra o sobrevalorados sin una única tendencia.

La CR-1899 funcionó durante treinta y un sesiones en las que se discutieron los resultados de los grupos de trabajo particulares que abordaron distintas clases de productos. Cada grupo representaba a comerciantes y al menos dos gremios directamente interesados; además, los miembros de cada subcomisión, por un lado, escucharon a quienes reclamaran (en persona o vía correspondencia) por los aforos que afectaban directa o indirectamente sus negocios, y, por el otro, consideraron investigaciones previas como los estudios preliminares de la Bolsa de Comercio y los informes de las sociedades industriales y de las cámaras extranjeras de comercio. Una novedad de la CR-1899 en relación a su antecesora fue la colaboración de los vistas de Aduana en los debates sobre ciertos artículos que requerían de su expertise. La intervención de estos funcionarios fue muy útil para evitar englobamientos en categorías que reunían distintas calidades, así materias baste recordar que las Comisiones Revisoras no tuvieron taquígrafo para ajustar gastos y que en la CR-1899 se sugería imprimir en el mimeógrafo de la Dirección de Estadística para evitar los costos de una imprenta privada (CR-1899, Acta $\mathrm{N}^{\circ} 5$ ). 
como para alertar sobre trucos usados por los despachantes aduaneros para que sus clientes paguen menos impuestos. ${ }^{5}$ Una vez reunida la mayor información posible, cada grupo se expedía, haciendo lugar a dictámenes de minoría, en caso de que alguno de los miembros no estuviera de acuerdo total o parcialmente con las conclusiones. Finalmente, la Comisión Revisora tomaba en cuenta estos despachos y también se hacía eco de los reclamos sobre la situación actual o las propuestas de las subcomisiones. Tal fue la participación de distintos actores y sectores en la CR-1899 que su presidente la retrató -tal vez exageradamentecomo "una junta popular" (Carta del Presidente de la CR-1899).

Ya en la primera década del siglo XX existían más de 3.800 partidas de aforos y no se había logrado crear una comisión permanente que los revisara, tal como se había previsto originalmente, emulando a otros países con tradición en ello, como Francia. En 1907 se volvió a llamar a una Comisión Revisora, esta vez bajo la dirección de Emilio Frers. El contexto de fondo, según las explicaciones vertidas en los informes de la CR-1907, fue que el gobierno de José Figueroa Alcorta estaba alarmado por el encarecimiento del costo de vida a partir del aumento de precios de artículos de primera necesidad, lo que repercutía en aumento de salarios, acrecentando los costos de producción, de por sí altos por la suba en los precios de insumos, materiales, etc. (Carta de Presidente de CR-1907). Es decir, la formidable expansión que la Argentina, en particular en el litoral, estaba experimentando en términos materiales no había aplacado los conflictos sociales, políticos y económicos ni evitado la recurrencia de las crisis (Gerchunoff, Rocchi y Rossi). Y con el cambio de siglo, había crecido la preocupación en los gobiernos conservadores, y en todo el espectro político, por la "cuestión social" (Zimmermann), aspecto que había sido esgrimido por algunos legisladores de provincia en las que el sector industrial no era fuerte para defender su posición proteccionista (Rocchi, "El imperio").

Con gran impulso iniciático, la CR-1907 se propuso discutir varios temas que, revisados por sus predecesoras, seguían sin resolverse, a saber: la conveniencia de mantener ambos tipos de aranceles (ad valoremy específicos), la clasificación de mercaderías según distinta calidad y la posibilidad de considerar escalas mínimas y máximas en los aforos, la liberación de derechos y los gravámenes accesorios. Asimismo, debido al contexto arriba señalado, la CR1907 procuró estudiar concretamente los artículos de primera necesidad "para los obreros y la población menos acomodada" (alimentos, vestidos, habitación suscitaron destacaron los artículos de cuero, armería y cerámica (CR-1899, Actas No 10,14 y 16). 
e instrumentos de trabajo manual) así como "para las industrias nacionales" (materias primas, materiales para la construcción, envases, medios de transporte, etc.). Por otra parte, la CR-1907 buscó informar sobre los efectos de las reformas sobre el precio de artículos en plaza y sobre el erario público, observando el aumento o la baja de la renta aduanera así como las compensaciones directas o indirectas (CR-1907, Actas $\mathrm{N}^{\circ} 1$ y 2).

En junio de 1907, la Comisión Revisora presentó a Eleodoro Lobos, entonces Ministro de Hacienda, los resultados de la Primera Parte, vinculada a la Tarifa de Avalúos. El trabajo versó principalmente sobre los aforos que daban lugar a reclamos por parte del comercio o de la industria. Además, modificaron algunos que carecían de lógica. Los antecedentes de la CR-1907 fueron las tareas realizadas previamente por las CR-1894 y CR-1899, así como la Comisión de la Cámara de Diputados que preparó el presupuesto para 1903. Sobre el criterio para determinar la Tarifa de Avalúos, el problema no solo fue hallar precios de mercado, sino encontrar términos equitativos, dadas las diferencias en calidades. Las subcomisiones trabajaron con dos vocales o más y buscaron datos en asociaciones comerciales e industriales, en la Unión Industrial Argentina, las cámaras de comercio nacionales y extranjeras, legaciones foráneas, la Liga de Defensa Comercial, y los vistas de Aduanas (CR-1907, Acta No 11), entre otros. Los dictámenes emitidos por cada subcomisión fueron discutidos partida por partida. Una novedad fue que la CR-1907 propuso evitar la "declaración del valor" cuando los bienes importados no se hallaban en la Tarifa de Avalúos, pues daba lugar a abusos y a cuestionamientos cruzados entre la Aduana y los importadores, lo que generaba dilaciones en trámites y despachos. A cambio, recomendó la "certificación de valor" mediante comprobantes consulares (CR1907, Acta No 12). Finalmente, en noviembre de 1907 se elevó al nuevo Ministro de Hacienda, Manuel de Iriondo, los análisis de la Segunda Parte, dedicada al estudio de la tasa de impuesto y otras disposiciones aduaneras.

\section{LA COMPOSICIÓN Y LA PARTICIPACIÓN EN LAS COMISIONES REVISORAS}

En la política de la época, en general se observa que los radicales y los socialistas fueron más proclives al librecambismo, a fin de abaratar el consumo de artículos de primera necesidad, por su vínculo con las clases medias urbanas y los trabajadores, respectivamente. Estos sectores políticos confiaron en la industrialización como senda al crecimiento, pero por vías ajenas a las tarifas aduaneras. En cambio, el Partido Autonomista Nacional -más allá de algunos matices en sus figuras- promovió la industrialización con protección comercial 
(Caravaca 43-51; Gerchunoff y Llach 37-42; Hora, "La política económica"; Rocchi, "El imperio"). Sin embargo, cuando quienes estuvieron a cargo del Poder Ejecutivo convocaron a los integrantes de las Comisiones Revisoras procuraron perfiles diversos, con representación de distintos sectores e intereses de la sociedad y de la economía y, como ya hemos adelantado en la sección anterior, hubo una variada participación en las diversas sesiones, lo que consta en las actas que hemos consultado para esta investigación.

La CR-1894 se compuso con el senador autonomista por la provincia de Santa Fe (Lorenzo Anadón), como presidente, y como vocales: cuatro industriales (Ventura Martínez Campos, Ángel Estrada, Juan Videla y Luis Zuberbülher -ya que habían renunciado Santiago Baibiene y JoselínHuergo), tres comerciantes (Antonio Lanusse, Remigio Tomé y Francisco Cayol), el Procurador del Tesoro (Enrique García Mérou), un funcionario de las estadísticas (Francisco Latzina), un ex ministro de Hacienda (Emilio Hansen) y dos representantes de la prensa (Agustín de Vedia y Enrique Kohn). Desde luego, la composición relativamente variada no estuvo exenta de controversias. En la CR-1894, como en las sucesoras, existieron acusaciones de que predominaron determinadas tendencias ideológicas. Así, Martínez Campos, Presidente del Club Industrial, elaboró un informe en disidencia en relación a la Subcomisión de Mercaderías Generales, en el que expuso que consideraba que había primado el librecambio. Hansen discutió el informe por la ausencia de datos que sostuvieran empíricamente la postura de Martínez. Asimismo, Hansen confirmó que la Subcomisión había cuidado las industrias nacionales, pero que "no podía favorecerse a unos pocos sobre muchos". A este respecto, Anadón respondió que la CR-1894 se había formado imparcialmente a propuesta del Ministerio de Hacienda sin propósito deliberado de favorecer a ningún gremio, estando conformada con prescindencia de toda doctrina económica, a excepción de él mismo "que venía con bandera desplegada" -en alusión a su conocida postura librecambista, lo que lo había transformado en el principal exponente del librecambio en el Senado por aquellos años (Rocchi, "El imperio")-, pero que no había intervenido bajo el deseo de que prevaleciera la mayor imparcialidad. A su turno, Tomé y Cayol defendieron que ninguno de ellos había tenido ideas preconcebidas ni la intención de imponer doctrina económica alguna (CR-1894, Acta $\mathrm{N}^{\circ} 16$ ).

Por su parte, la CR-1899 estuvo presidida nuevamente por Anadón y compuesta por dos diputados oficialistas (Ponciano Vivanco, de la provincia de Córdoba y José L. Llobet, de la provincia de Santa Fe), el presidente de la Dirección de Rentas (Nicolás Achával), un funcionario de la Dirección de Rentas (Manuel Camelino), el jefe de Vistas de la Aduana de ciudad de Buenos Aires (Benjamín Frías), el presidente de la Unión Industrial Argentina 
(Francisco Seguí), un miembro de la Unión Industrial Argentina (Juan Videla), el presidente de Industrias Fabriles Confederadas (JaboboPeuser), el presidente de la Cámara de Comercio española (Antonio Laclaustra), el presidente de la Cámara de Comercio francesa (Edmundo Bellemare), el presidente de la Cámara de Comercio italiana (Eduardo Bérgamo), el jefe de la Dirección General de Comercio e Industrias del Ministerio de Agricultura (Federico Cibils) y un empresario (Ernesto Lalanne) (Decreto Presidencial). En la quinta sesión (CR-1899, Acta $\mathrm{N}^{\mathrm{o}}$ 5), se comunicó el nombramiento del vocal de la Sociedad Científica Argentina (Domingo Noceti), de un periodista y abogado, de una rica familia empresaria (Francisco Uriburu (hijo)), y del anterior participante Cayol, en reemplazo de Peuser, Cibils y Lalanne, tras su renuncia. Quedó como secretario José Varas, quien ya había cumplido este rol en la CR-1894.

Nuevamente, las acusaciones cruzadas sobre la primacía de determinadas ideas económicas tuvieron lugar. Así, durante la sesión preparatoria de la CR1899, (CR-1899, Acta $\mathrm{N}^{\mathrm{o}}$ 1) Lacaustra y Bellemare insistieron en que se abaratara la vida de los trabajadores, pues los aforos eran mayores a los precios reales en general, entre $20 \%$ y $30 \%$, aunque había casos extremos, como los tejidos que superaban el $60 \%$. Desde su perspectiva, el proteccionismo era exagerado $\mathrm{y}$ funesto porque creaba una industria artificial y perjudicial al consumo y al comercio. Sin embargo, durante la segunda sesión (CR-1899, Acta $\mathrm{N}^{\circ} 2$ ), se cuestionó la disparidad en la representación de intereses, pues Cibils objetó que hubiera más representantes del estado y del comercio que de la industria. Entonces, como en 1894, Anadón defendió la ecuanimidad y la objetividad en los estudios de la CR-1899.

La CR-1907 contó con un presidente que había sido relevante en la Sociedad Rural Argentina y ex Ministro de Agricultura (Emilio Frers) y, como vocales, algunos que ya habían actuado en anteriores Comisiones Revisoras, como Lanusse, Hansen, Cayol, Zuberbülher y Latzina, y nuevos integrantes, como el Jefe de la Dirección General de Comercio e Industria del Ministerio de Agricultura (Ricardo Pillado), el jefe de la Dirección de Economía Rural y Estadística del Ministerio de Agricultura (Emilio Lahitte) y el Jefe de Vistas de Aduana (Pedro L. Medina). Otra vez, el secretario fue Varas. Aunque Pillado, Lahitte y Latzina, por ejemplo, han sido reconocidos - con sus matices- como defensores del librecambio (González Bollo), según Frers, ningún gremio ni industria tuvo representantes directos en la CR-1907. En efecto, en el balance final sobresalió la idea de que "la comisión (...) no ha reparado en ninguna clase de interés comercial, ni industrial ni aún fiscal, prefiriendo poner una base cierta, justa e inconmovible a las deliberaciones del legislador cuando lleguen para él la tarea y la responsabilidad de fundar en ella la proporcionalidad de los 
gravámenes aduaneros" (CR-1907, Acta No 15). Para Frers, la prueba de que las posturas librecambistas no se impusieron estuvo en que no hubo reformas sustanciales. En este sentido, se respetó el nivel del 31\% de los aranceles promedio, lo cual era extraño para el presidente de la CR-1907, dado que la misma estuvo conformada en su mayoría por hombres que profesaban pública y notoriamente ideas económicas liberales, o por lo menos distantes de los excesos fiscales y protectores. Incluso, Frers hizo comparaciones y observó que Argentina estaba por encima de los niveles promedio de otros países $(8 \%$ Alemania, 7\% Francia, 5.3\% Reino Unido, 7.5\% Japón, 17\% Australia, 15.6\% Canadá y $24.4 \%$ Estados Unidos), ${ }^{6}$ y en particular en sectores específicos, como textiles y alimentos, afectando artículos de primera necesidad (Carta de Emilio Frers). Además, se reconoció que la CR-1907 había escuchado a todo aquel que hubiera querido presentar objeciones o reclamos (Carta de Emilio Frers).

En cuanto a la participación, las Comisiones Revisoras recibieron como informantes -en exposiciones orales o a través de correspondencia- a miembros -nacionales o extranjeros- del comercio, de la industria, de las actividades agropecuarias, de las economías regionales, de otros gobiernos o del propio gobierno. En todas las Comisiones Revisoras intervinieron funcionarios de la Dirección de Rentas para observar el impacto que sobre la recaudación aduanera tendrían las modificaciones. Desde el sector privado, un gran número de productores y comerciantes elevaron sus quejas, solicitudes, opiniones, acuerdos o discordancias. Fueron llamados en ciertas circunstancias para ilustrar sobre determinados bienes, en base a sus precios corrientes, a sus características de fabricación y diversidad de calidades (por ejemplo, las diferencias entre pino de tea y pino blanco (CR-1894, Acta $\mathrm{N}^{\mathrm{o}} 13$ ) o entre sillas de fabricación norteamericana y otras alemanas) (CR-1894, Acta $\mathrm{N}^{\circ}$ 9)). En algunos casos, se enfrentaron en las mismas sesiones para dar cuenta de sus posiciones proclives al librecambio o al proteccionismo (por ejemplo, en la CR-1894 expusieron tanto representantes del Centro Azucarero como importadores de azúcares y vinos (CR-1894, Acta $\mathrm{N}^{\mathrm{o}} 11$ ), o representantes de vitivinicultores mendocinos y sanjuaninos versus miembros de la Cámara de Comercio Francesa o importadores de vinos españoles (CR-1894, Actas $\mathrm{N}^{\mathrm{o}} 18$ y 20)). En las sesiones se presentaron particulares o enviados de firmas para pedir por mayor desenglobamiento de los productos en las categorizaciones o modificación de aforos, aportando catálogos, muestras y facturas para justificar sus requerimientos (CR-1894, Acta N²0; CR-1899, Acta

6 Estas comparaciones coinciden con otras que ha realizado la historiografía para mostrar que América Latina antes de la Gran Depresión era la región más proteccionista del mundo por razones fiscales (Coatsworth y Williamson; Clemens y Williamson). 
$\mathrm{N}^{\mathrm{o}}$ 6; Carta de Emilio Frers). Además de la ya mencionada presencia de delegados de las Cámaras de Comercio de ciertos países generalmente para argumentar contra barreras proteccionistas elevadas sobre artículos de sus procedencias, se debe indicarla participación de diplomáticos extranjeros cuando algún caso lo ameritó.

Aunque todas las Comisiones Revisoras se desempeñaron bajo patrones más o menos parecidos, sí es preciso señalar algunas diferencias. Por un lado, las presiones de los representantes de la agroindustrias fueron mayores en la CR1894 que en sus sucesoras; por el otro, a partir de las CR-1899 se multiplicaron las voces a favor del proteccionismo industrial, en particular de los emprendimientos característicos de la ciudad de Buenos Aires y alrededores (por ejemplo, textiles, alimentos, bebidas, fósforos, calzado), viabilizadas por individuos, gremios o asociaciones o empresas. Asimismo, con el paso del tiempo se visibilizaron las demandas por mayor liberalización hechas por los consumidores (por ejemplo, prensa (CR-1894, Acta No 22), Club de Cazadores (CR-1899, Acta No 14), Liga de Defensa Comercial (Carta de Emilio Frers)). Por su parte, las voces de los exportadores, organizadas en torno a entidades como la Sociedad Rural Argentina o fragmentarias según las necesidades de negocios particulares (por ejemplo, algún exportador saladerista de Entre Ríos o un exportador de hierro viejo), presentes en la CR-1894 (CR-1894, Acta No 30), se diluyeron en la CR1899, apenas invocadas para constatar precios de "frutos del país" (a través de la Cámara Mercantil o la Sala Comercial del Once de Septiembre (CR-1899, Acta $\mathrm{N}^{\mathrm{O}}$ 17)) y desaparecieron en la CR-1907, lo que se explica por la progresiva liberalización de las exportaciones.

\section{PRINCIPALES TEMAS Y MATERIAS DE LAS COMISIONES REVISORAS}

Así como en la sección anterior hemos mostrado brevemente quiénes formaron parte de las sucesivas Comisiones Revisoras y hemos expuesto la diversidad de actores que participaron de las mismas, en esta abordaremos algunos de los principales temas transversales a las tres experiencias y ejes centrales de los debates sobre los alcances y las limitaciones de la política arancelaria del período.

\section{a. Los aspectos técnicos del arancelamiento}

Los tópicos obvios que abordaron las distintas Comisiones Revisoras fueron, por un lado, la revisión de los aforos y de los aranceles para mantenerlos, 
bajarlos o incrementarlos. Y, por el otro, las reglamentaciones aduaneras en relación a las mercaderías no enumeradas en la Tarifa de Avalúos, a la forma de pago de los derechos de importación, a la aplicación de la cláusula de Nación Más Favorecida, al reingreso de exportaciones, al tránsito terrestre de bienes, a la moneda usada para liquidar aranceles, a la declaración de valor de artículos no registrados, y al secuestro y al pesaje de productos (por ejemplo, en la vestimenta y en las bebidas) (CR-1894, Actas No 29 y 30).

Entre las cuestiones técnicas, fueron recurrentes las referencias a agregar los distintos derechos que pesaban separadamente sobre las mercaderías a fin de agilizar los trámites de contabilidad (Carta de la CR-1894). Asimismo, entre esos derechos adicionales, se propuso elevar el referido a "estadísticas y contralor" para que el Estado argentino contara con más recursos materiales y humanos para procesar la información. Debido a su papel como guía de la estadística oficial, Latzina, involucrado en las tres Comisiones, obviamente fue el mayor defensor de esta medida. La CR-1907 fue la más directa proponiendo $0.3 \%$, en lugar del $0.1 \%$ existente (Carta de Emilio Frers), idea que posteriormente no se implementó.

También hubo debates sobre la conveniencia de uniformar el tipo de aranceles a aplicar, dada la convivencia de derechos ad valoremy derechos específicos. Latzina (1886) fue temprano defensor de los segundos, dado que eran ampliamente usados por los países europeos y resultaban más prácticos en términos aritméticos. Las opiniones a favor de este tipo de derechos los consideraban más científicos porque eran directos, claros y netos, a diferencia de los derechos ad valorem que generaban errores en la contabilidad. Por su parte, miembros de las Comisiones Revisoras, como los de la de 1894 al tratar los comestibles, u otros que formaron parte de la de 1907, como Medina, Cayol, Hansen, Frers y Pillado, defendieron los derechos ad valorem, dado que eran mejores para que los legisladores conozcan la proporcionalidad del arancel sobre el valor de los artículos (CR-1907, Acta $\mathrm{N}^{\mathrm{o}} 30$ ), al tiempo que evitaban exageraciones ocultas bajo un valor absoluto nominal no representativo del precio de mercado - por ejemplo, según la CR-1907, gracias a los derechos específicos, en la práctica el papel pagaba el $200 \%$ de su valor y los residuos de petróleo pagaban 400\% (CR-1907, Acta $\mathrm{N}^{\mathrm{o}} 16$ ). Esta idea fue creciendo y ganando en adeptos al punto de que la CR-1907 propuso convertir todos los derechos específicos en ad valorem, lo que no prosperó, ya que la coexistencia de ambos tipos de aranceles continuó (Ley de Aduana de 1923). Estudios sobre la materia indicaban que cualquiera de las opciones en la época conllevaba desventajas. Así, los derechos ad valorem eran potencialmente fraudulentos dado que el introductor podía declarar menor calidad de la mercadería, lo que 
podía contrarrestarse según los conocimientos de los vistas de Aduana, mientras que los derechos específicos, aplicados en Argentina mayormente a los bienes de consumo masivo, remitían a montos fijos que no reflejaban las variaciones de los valores corrientes (Pessagno 48).

Tampoco hubo unanimidad al debatir sobre la forma de aplicar los derechos, pues en el mundo iba progresando la declaración de valor, mientras en Argentina, como en el resto de América Latina, continuaba la valuación oficial (Federico y Tena). Durante la CR-1899 se manifestó que en Estados Unidos el despacho aduanero se hacía por la primera opción porque los valores declarados estaban respaldados por facturas certificadas por los cónsules y porque allí consuetudinariamente se le daba "mayor importancia a los juramentos" (CR1899, Acta $\mathrm{N}^{\mathrm{o}} 10$ ).

Finalmente, las calidades, así como el lugar en la catalogación, constituyeron un tema sensible por su incidencia en el pago de aranceles (por ejemplo, la CR-1894 debió relocalizar los carros livianos estadounidenses para el campo (CR-1894, Acta No 7), y la CR-1899 debatió si las carpetas y cortinas formaban parte de los Tejidos, que pagaban $25 \%$ ad valorem, o si debían pasar a Confecciones, cuyo arancel era el doble (CR-1899, Acta $\left.\mathrm{N}^{\mathrm{o}} 8\right)$ ). Las Comisiones Revisoras trabajaron en reducir partidas para evitar confusiones y agilizar los despachos. Sin embargo, este proceso tropezó con la existencia creciente de calidades diversas. A medida que crecía el mercado de consumo argentino, se hacía cada vez más difícil el proceso de englobamiento de las categorías y hubo referencias para distinguir entre "lo ordinario, lo regular y lo fino", por ejemplo, en artículos de mercería o de perfumería. Las principales discusiones en torno a las dificultades en la agregación de calidades bajo el mismo rótulo se dieron en vestimenta, comestibles y bebidas, dado que una mala decisión podía encarecer bienes de consumo masivo o abaratar artículos selectos con alto impacto en la economía (CR-1899, Actas No 5, 11 y 12; CR-1907, Actas No 4 y 9). Ni siquiera la CR-1907 logró resolver este problema, que quedó pendiente para estudios futuros (Carta de J. Figueroa Alcorta y E. Lobos al Congreso Nacional).

\section{b. Las necesidades fiscales}

Dos flagelos afectaban la recaudación fiscal en el comercio exterior: el contrabando y la evasión. El primero tendía a producirse con productos relativamente caros (alhajas y relojes, piedras preciosas (CR-1894, Actas $\mathrm{N}^{\mathrm{o}} 1 \mathrm{y}$ 2), sombrerería, azafrán (CR-1894, Acta No 28), tabaco (CR-1894, Actas $\mathrm{N}^{\mathrm{o}} 18$, 20 y 22; CR-1899, Acta No 16), o cortinados (CR-1899, Acta $\left.\mathrm{N}^{\circ} 18\right)$ ) y, aunque no hubo importantes denuncias al respecto, cabe decir que se conocía su existencia 
dada la falta de vigilancia en algunas costas y puntos de frontera (Fernández; Rayes, "The Other Side"). El segundo problema afectaba particularmente a bienes para los que los funcionarios aduaneros requerían de conocimientos técnicos (objetos de arte y fantasía (CR-1894, Actas $\mathrm{N}^{\mathrm{o}} 21,22$ y 23), artículos de droguería (CR-1894, Acta $\mathrm{N}^{\circ} 28$ ), mueblería y tapicería finas (CR-1899, Acta $\mathrm{N}^{\circ}$ 20; CR-1907, Acta No 7)). En efecto, para mitigar la evasión fiscal se recomendó reiteradamente que ciertos productos únicamente ingresaran por Aduanas con personal especializado, de preferencia la de Buenos Aires.

El impacto de las medidas aduaneras en la recaudación fiscal implicaba discutir los aforos y los aranceles. Sobre los valores oficiales, problema visibilizado para una diversidad de bienes especialmente en las CR-1899 y CR-1907, la polémica giró, por un lado, acerca de qué precios considerar como referentes de los mercados (en particular en comestibles, ferretería, artículos de mercería y bazar, frutos del país). En algunos casos, se sugirió revisar las tarifas de otros países (perfumería (CR-1899, Acta $\mathrm{N}^{0}$ 26) y ferretería (CR-1899, Acta $\left.\mathrm{N}^{\mathrm{o}} 23\right)$ ); en otros, buscar en casas comerciales e importadoras (confecciones (CR-1907, Acta $\mathrm{N}^{\circ}$ 5)), en catálogos o en facturas (tejidos (CR-1899, Acta $\mathrm{N}^{\circ}$ 7), sombreros (CR-1907, Acta $\mathrm{N}^{\mathrm{o}}$ 9)). El inconveniente que existía en estos últimos era que podían estar alterados por descuentos o motivos estacionales $y$, en consecuencia, no reflejar los verdaderos precios de plaza. Por otro lado, hubo discusiones sobre la declaración de valor para determinados artículos (maquinaria (CR-1899, Actas $\mathrm{N}^{\circ} 22$ y 24), mueblería o productos de mercería finos, como los cuchillos con mango de marfil (CR-1899, Acta $\mathrm{N}^{\mathrm{o}} 26$ )) y las posibles pérdidas en los ingresos estatales (CR-1899, Acta No 23).

Las sucesivas Comisiones Revisoras se limitaron a controlar los efectos de los aranceles al comercio exterior, aunque hicieron referencias, particularmente la CR-1894 debido al apremio en los ingresos públicos, a la necesidad de buscar alternativas en impuestos indirectos al consumo -bebidas, lamparería, tabacos, fósforos, etc.-, dada la imposibilidad de aplicar en aquella época otra clase de recursos como el impuesto a la renta (Sánchez Román). En las CR-1894 rebotó la todavía vigente discusión sobre los gravámenes a productos nacionales que habían crecido a la sombra de la protección arancelaria, como el alcohol justificado, a diferencia de otros como los azúcares, por principios higienistas o moralizadores (Moyano).

Desde la arista fiscal, los extremos -aranceles muy altos o productos libres-fueron ampliamente discutidos. Por un lado, se consideró que los derechos aduaneros fueron los culpables de la caída de determinadas importaciones (por ejemplo, cueros y pieles curtidas, zapatería, vestimenta, talabartería o tabaco). En las distintas Comisiones Revisoras existió preocupación por los niveles 
máximos de los aranceles, en algunos casos, por razones fiscales más que por cierto espíritu liberal. La CR-1894 indicó que el derecho máximo, en apariencia de $60 \%$, resultaba magnánimo cuando se estudiaban los aforos o las imposiciones específicas, dado que se multiplicaba por dos o cuatro el precio del artículo procedente del extranjero. La opinión general era que ello conspiraba en favor del contrabando y que iba en detrimento del crecimiento de la importación y de la mayor utilidad fiscal (Carta de la CR-1894). Para la CR-1899, este problema fue concreto con los Tejidos, puesto que existieron tres intereses en pugna: los comerciantes que querían bajar el aforo, los industriales que buscaban subirlos y el fisco, que tenía una posición variable en función de la renta (CR-1899, Acta $\mathrm{N}^{\mathrm{o}}$ 7). De hecho, en la CR-1907 se concluyó que la baja de la importación de tejidos de lana desde finales de la década de 1890 se debía a altas tarifas, perjudicando al fisco (CR-1907, Actas $\mathrm{N}^{\circ} 3$ y 4).

Por el otro, las CR recomendaron el pago de aranceles, aunque fuera mínimo, para todos los productos. Algunos artículos fueron trasladados por la CR-1894 a distintas categorías para que tributen (azogue, corteza de alcornoque, hilados de lana o algodón, libros o lúpulo (CR-1894, Acta $\mathrm{N}^{\circ}$ 30)). También afloró la discusión sobre el arancelamiento del material didáctico (CR-1894, Acta $\mathrm{N}^{\mathrm{o}}$ 7). La CR-1907 recomendaba aforar productos por similares o que declaren valor, pero evitar el ingreso irrestricto. Además, fue la que más alertó sobre los excesos rayanos con el contrabando, como el ingreso de materiales médicos para hospitales (CR-1907, Actas $\mathrm{N}^{0} 9$ y 13), materiales para la construcción de obras públicas, útiles para establecimientos educativos u objetos de culto para instituciones religiosas (CR-1907, Acta $\left.\mathrm{N}^{\circ} 24\right)$. Ello estaba en línea con la progresiva eliminación de eximiciones que el Poder Ejecutivo podía otorgar en casos en que se justificara por razones benéficas o científicas (Rayes, "The Trade Policy”). Las discusiones sobre el pago obligatorio de algún tipo de arancel llevaron a plantear, incluso, la relación entre la industrialización y el principio de igualdad fiscal en 1907. En este sentido, la Subcomisión de Materias Primas recomendó suprimir la prescripción por la que un producto que pagaba $25 \%$ cuando era introducido por un comerciante pudiera salir de Aduana pagando $5 \%$ si el que solicitaba el despacho era un industrial. En todo caso, se sugirió que las materias primas para la industria se agruparan en una única sección del arancel, con las mayores especificaciones posibles (los productos no aforados en el arancel caerían bajo un arancel general (CR-1894, Acta $\left.\mathrm{N}^{\circ} 30\right)$ ).

Cabe señalar que las exportaciones fueron analizadas con una perspectiva distinta a las importaciones. Si en la década de 1870 casi todas las exportaciones pagaban impuestos, desde mediados de la década de 1890, solo la mitad estuvieron gravadas y, a partir de 1906, quedaron libres. Hemos considerado que 
la liberalización de las exportaciones quizás se haya debido al gran crecimiento que experimentaron, tanto en volumen como en valor (Rayes, "La estadística"), $y$ al rol que el sector exportador tuvo en el crecimiento del PBI (Winograd y Véganzones) y como dinamizador de la economía en general (Kuntz-Ficker y Rayes). Liberar las exportaciones de los aranceles era una forma de alentar las actividades surgidas como eslabonamientos (Gallo, "Agrarian"; Geller), y daba la posibilidad de que el Estado pudiera sustentarse con otras fuentes. La CR-1894 consideró que las exportaciones debían quedar exentas de derechos para hacerse más competitivas en un mundo en que los precios de esta clase de bienes estaban en baja, pero también reconocía que el fisco podía necesitar estos recursos, por lo que mantuvo el $4 \%$ ad valorem. Se propuso dejar libre el ganado vacuno en pie con destino a países limítrofes y recargar solo el que iba a Europa. También se sugirió un arancel para la exportación de hierro viejo, por temor a que su salida perjudique a la industria nacional (CR-1894, Acta $\mathrm{N}^{\circ} 30$ ). La CR-1899 recomendó aumentar los aforos de ciertos bienes exportados, aunque algunos miembros, como Bellemare y Videla, entendieron que los precios altos en el mercado internacional respondían más a situaciones coyunturales, como la pérdida de cosecha en Australia o la guerra anglo-bóer (1899-1902) (CR-1899, Acta N ${ }^{\circ}$ 17). Finalmente, la CR-1907 no trató este tema porque desde 1906 las exportaciones quedaron completamente libres y ello no se cuestionó.

Desde luego, reglamentar el nivel tarifario tuvo impacto en los sectores productivos por su necesidad de insumos o bienes de capital que llegaban desde el exterior. Las actividades agrícolas y ganaderas, orientadas tanto al mercado interno como a las exportaciones, dependieron de la entrada de algunos productos. Algunos miembros de la CR-1894, como Tomé, Vedia y Kohn, sostuvieron que la agricultura era nueva y había que impulsarla bajando los aranceles de la arpillera (CR-1894, Acta N ${ }^{\circ}$ 5); también García Mérou, Cayol, Videla y Hansen pidieron la baja de los derechos a los alambres para cercos y arados (CR-1894, Actas $\mathrm{N}^{\mathrm{o}} 12,13$ y 17). Una vez consolidado el sector agropecuario, la CR-1907 consideró la supresión de la libre importación de bolsas de arpillera para cereales y de bolsas de algodón para carnes congeladas y harina para la exportación (CR1907, Actas $\mathrm{N}^{\mathrm{o}} 3$ y 4), y Pillado insistió en que no cualquier producto podía tratarse como abono, ya que así sorteaban impuestos (CR-1907, Acta $\left.\mathrm{N}^{\circ} 14\right)$. Es decir, a medida que el sector agropecuario se consolidaba y expandía -y que sus productos quedaban libres de aranceles-, las CR propusieron que sus insumos, bienes de capital y bienes intermedios pagaran impuestos.

También el sector industrial exigía rebajas o anulación de derechos sobre artículos necesarios para su proceso productivo. Un problema relevante desde la CR-1894 en adelante fue el gravamen a las maquinarias. Cayol y Anadón 
cuestionaron que se perjudicaran a las pequeñas máquinas, destinadas a pequeños establecimientos industriales, con aranceles de $25 \%$ ad valorem, mientras las grandes máquinas estaban gravadas con $10 \%$ ad valorem. Hansen, en cambio, sostenía que muchas de las pequeñas herramientas o útiles sí se fabricaban en el país y el gravamen era un estímulo fiscal (CR-1894, Acta $\mathrm{N}^{\mathrm{o}} 15$ ). Por su parte, García Mérou criticaba que se favorecieran las "nuevas industrias", dado que en la Aduana no era posible distinguir qué material se dirigía a antiguos o nuevos establecimientos (CR-1894, Actas $\mathrm{N}^{\mathrm{o}} 12,13$ y 17). Los representantes del sector industrial participaron activamente en las discusiones de las Comisiones Revisoras. Así, las fábricas de cerveza solicitaron la baja de aforos y derechos de las cápsulas de plomo (CR-1894, Acta $N^{\circ}$ 25). En la CR-1899 se pidieron rebajas en aranceles de artículos de droguería -como el aceite de coco o de palma, usado como tinte, y el azufre, empleado tanto en viñedos, para fabricar pólvora y como anti-sárnico (CR-1899, Acta $\left.\mathrm{N}^{\circ} 29\right)$-o de corchos, utilizados en la industria cervecera y vinícola (CR-1899, Acta No 31). Ya en la CR-1907 se plantearon las diferencias entre los petróleos por sus distintos usos industriales y cortes, y la necesidad de rebajar solo aquellos que pudieran refinarse en el país (CR-1907, Acta $\mathrm{N}^{\circ}$ 13).

\section{c. La protección a la industria nacional}

Posiblemente uno de los puntos más controversiales en la literatura acerca de la política arancelaria sea su impacto en la protección a la industria nacional. Aunque la medición de este sector durante la época es complicada dada la ausencia de datos fiables y seriados (Belini; Harriague y Rayes) es importante reconocer que hay varios indicios sobre su creciente relevancia, lo que explica la centralidad del sector en muchos de los debates dentro de las Comisiones Revisoras y la necesidad de contar con información fidedigna para concluir sobre los niveles de protección de diversos rubros. En este sentido, tempranamente la CR-1894 alertó sobre la conveniencia de realizar censos industriales de forma periódica. Todavía en la CR-1907, Frers insistía en la dificultad para conocer si la protección aduanera en cada rama era correcta, debido a la falta de información -proporción de la producción nacional en relación a las importaciones, materias primas empleadas (en qué cantidades y de qué procedencia), número de fábricas, aporte del capital, volumen de producción manufacturera, competencia, costos, precios, y mano de obra, entre otros (Carta del Presidente de la CR-1907).

Debemos señalar que el proteccionismo industrial como idea hunde raíces antes de la CR-1894. La crisis de 1866 despertó en un grupo de ganaderos, vinculados al lanar, la necesidad de plantear medidas para fomentar la industria 
textil local. Esta iniciativa, avalada también por pequeños y medianos artesanos, industriales y comerciantes, fue recuperada ante la crisis internacional de 1873 y repercutió en los debates parlamentarios de 1875 y 1876 a propósito de las leyes aduaneras (Chiaramonte). Pero, si en la década de 1870 la industria era un sector modesto en la economía argentina debido al tamaño del mercado y a los costos del transporte, sus tasas de crecimiento superaron a las del sector rural en el PBI a partir de los últimos años del siglo XIX (Cortés Conde, La economía argentina).

Desde luego, no facilitó las tareas de las Comisiones Revisoras el cuadro heterogéneo del sector, en términos de mano de obra, capital, tecnología, localización y alcance comercial. El crecimiento manufacturero fue motorizado por el mercado interno -en particular en sectores como bebidas, alimentos, cigarrillos y confecciones. Las fábricas y los talleres asociados a esta actividad se concentraron mayormente en Buenos Aires y sus alrededores. Pero existieron otras industrias orientadas a las plazas domésticas, localizadas en economías regionales -los casos paradigmáticos son la vitivinícola cuyana y la azucarera norteña- y aquellas nacidas de las actividades exportadoras, como la cárnica y la harinera -ubicadas en la región litoral. ${ }^{7}$ En vísperas de la Primera Guerra Mundial, la producción nacional había logrado la sustitución de un elevado porcentaje del consumo aparente en bienes de la industria liviana (Dirección General de Comercio e Industria). Distintas explicaciones, todas consideradas en las Comisiones Revisoras, se dieron sobre el asunto, como el comportamiento del tipo de cambio, la protección arancelaria, y la expansión del mercado interno con la consecuente diversificación del consumo.

Dadas las fluctuaciones hasta inicios del siglo XX, el tipo de cambio fue tomado en cuenta para evaluar la protección a la producción doméstica y el impacto en la recaudación físcal. En este sentido, la CR-1894 calculó los derechos nominales y su relación con los derechos efectivos, que fueron más bajos desde 1885 a causa de la depreciación sostenida del peso en relación al oro (Alvarez). Esta estimación no se replicó en las siguientes Comisiones Revisoras debido a que la Argentina ingresó en una fase de conversión de su moneda en oro mediante la ley de 1899 (Della Paolera y Taylor), medida tomada ante la posible sobrevaluación del peso (Díaz Alejandro 290).

En contrapartida, y obviamente por la naturaleza de las Comisiones Revisoras, los debates sobre los efectos de los aranceles y de los aforos en el

$7 \quad$ Para una descripción actualizada del estado de la industria, véase Rocchi Chimneys; Hora "La política económica"; Belini. 
sector secundario fueron mucho más profundos. El eje de los argumentos a favor y en contra se centró en la viabilidad de los diversos casos y en los beneficios o perjuicios de importar esta clase de artículos. Por ejemplo, en la CR-1894 Cayol y Vedia apoyaban aranceles elevados para proteger la producción interna de calzado, al tiempo que Hansen y García Mérou querían rebajarlos para alentar el consumo y la importación, multiplicando los ingresos estatales. En cambio, Berduc insistía en que faltaban datos precisos para poder dictaminar (CR-1894, $A_{c t a} N^{0} 1$ ). Otro sector que generó debate por esos años fue la vestimenta. Martínez Campos y Cayol defendieron los aranceles altos para las camisas, los puños y los cuellos, dado que existía una industria local de buena calidad, a diferencia de Tomé que la comparaba desfavorablemente con la producción inglesa (CR1894, Actas $\mathrm{N}^{0} 3$ y 4). Por su parte, Hansen y García Mérou insistían en que los cueros y las pieles curtidas locales eran de menor calidad que los extranjeros, y que los zapateros preferían estos últimos, mientras Cayol sostenía que la vaqueta local era buena y que el sector solo adolecía de capitales (CR-1894, Acta $\mathrm{N}^{\mathrm{o}} 1$ ). Algo parecido acusaban quienes defendían la producción local de sombreros de lana (CR-1894, Acta $\left.\mathrm{N}^{\circ} 15\right)$, de sal para curtir cueros, de velas de estearina (CR-1894, Acta $\mathrm{N}^{\circ}$ 17), de papel prensa (CR-1894, Acta $\mathrm{N}^{\circ} 22$ ), de pequeñas embarcaciones (CR-1894, Actas No 12, 13 y 17), de cervezas (CR-1894, Acta N ${ }^{\circ}$ 23) y de placas fotográficas (CR-1894, Acta No 26), entre otros. En la CR-1899 también existieron opiniones diversas sobre la calidad de la producción local de, por ejemplo, guarniciones para caballos (CR-1899, Acta $\mathrm{N}^{\circ}$ 9), artículos de ferretería de goma (CR-1899, Acta $\mathrm{N}^{\circ} 23$ ), perfumes (CR-1899, Acta $\mathrm{N}^{\circ} 26$ ) o papeles (CR-1899, Acta N ${ }^{\circ} 27$ ), entre otros. Durante las sesiones de la CR1907 los casos más controversiales fueron los tejidos -aquí hubo una pulseada entre la Unión Industrial Argentina, que exigía altos aranceles para sostener la industria textil local, y la Liga de Defensa Comercial, que buscaba importar estos bienes (CR-1907, Actas No 3 y 4)- y el calzado (CR-1907, Acta No 4), que no había suscitado polémica en 1899 posiblemente por el bajo volumen importado. Otros bienes elaborados en el mercado doméstico y rechazados por algunos miembros de la CR-1907, debido a su baja calidad en comparación con sus similares foráneos, fueron -nuevamente- los sombreros de lana y de fieltro (CR-1907, Acta No 9), el mármol (CR-1907, Actas $\mathrm{N}^{\circ} 12,14$ y 15) y el papel (CR-1907, Acta $\mathrm{N}^{\circ} 8$ ).

El proteccionismo de la época ha estado generalmente asociado en la literatura a las industrias regionales, en particular al vino de Cuyo y al azúcar de Tucumán. Ello posiblemente se deba a que se trató de los casos más controversiales, junto -en menor medida-con la yerba y el tabaco del norte del país. No entraremos aquí en mayores detalles porque existe una extensa trayectoria de estudios al 
respecto; solo diremos que el incremento de las tarifas para estos bienes data de la década de 1880, cuando los aranceles dejaron de tener un uso meramente fiscalista para ser también herramientas de protección, pero no fue sino hasta el decenio siguiente que el Estado argentino intensificó su compromiso con el proteccionismo por convicción y necesidad (Hora, "La política económica"). La interpretación extendida es que se trató en todos los casos de sectores que no se beneficiaban directamente de la expansión exportadora pampeana y, por lo tanto, necesitaban del mercado interno para crecer, de manera que reclamaron, entre otras medidas, por tarifas elevadas (Balán).

El principal debate sobre la protección a las agroindustrias del interior se dio en la CR-1894. Entonces, los industriales azucareros se organizaron para defender su posición, logrando mantener las tarifas aduaneras protectoras a costa de impuestos internos (Guy). En las sucesivas Comisiones Revisoras se rubricó la impronta proteccionista para las agroindustrias del Interior, pero los debates fueron menos encendidos. Y aunque tuvieron apoyo de algunos miembros de las Comisiones Revisoras, otros se ampararon en la escasez de información para determinar su real efecto y dictaminar. Los informes proveen de suficiente material para profundizar acerca de estos sectores; aquí nos limitaremos a reseñar algunas ideas generales y recurrentes. Muy brevemente, la discusión sobre las tarifas de los vinos, que llevó varias sesiones de la CR-1894 (CR-1894, Actas $\mathrm{N}^{\mathrm{o}} 12,18,19,20,21,24$ y 27), implicó la participación de los ministros plenipotenciarios de los gobiernos español e italiano, así como de representantes de casas importadoras de distintos orígenes, y expertos en aspectos químicos. El debate no solo se centró en el nivel tarifario sino en los límites de graduación alcohólica. También en la discusión sobre la protección del azúcar participaron distintos representantes de la industria, del comercio y del fisco. Quienes defendían los altos aranceles argüían la necesidad del proteccionismo por la falta de capitales invertidos en los sectores, para resguardar fuentes de trabajo y contribuir al desarrollo de las provincias allende el Litoral. Quienes consideraban que los impuestos eran gravosos fundamentaron su posición en el carácter artificial -y poco competitivo en el mercado internacional- de la producción doméstica, así como en el encarecimiento del producto para los trabajadores y en la posibilidad de que las barreras protectoras significaran represalias por parte de algunos socios comerciales (CR-1894, Actas $\mathrm{N}^{\circ} 11,15,28$ y 29). Por su parte, el tabaco generó debates porque los productores misioneros defendían altos aranceles esgrimiendo la necesidad de apoyar emprendimientos locales y los puestos de empleo, al tiempo que a la CR-1894 llegaron informes mostrando cuán elevadas eran las tarifas y cómo ello había repercutido en el contrabando y la consecuente pérdida de renta para el fisco, lo que implicó la participación 
del ministro paraguayo (CR-1894, Actas $\mathrm{N}^{\circ} 18,20,22,23$ y 25). Finalmente, la yerba enfrentó a comerciantes, que demostraban que la mayor parte consumida procedía de Brasil o Paraguay, con los productores misioneros y correntinos, que exponían la relevancia de su protección (CR-1894, Acta Nº 19).

En algunos casos, la defensa de la industria se relacionó con el trabajo en varios sentidos. La protección de las fuentes de empleos con barreras altas a la importación estuvo vinculada a la atracción que el país podía ejercer en inmigración transatlántica. Pero también la conservación de las fuentes laborales implicaba garantizar el proceso de ampliación del mercado interno y la diversificación del consumo. Y, a diferencia de las industrias regionales, que estuvieron representadas en el Congreso nacional -en particular en el Senado-, a fines del siglo XIX los industriales porteños movilizaron a sus trabajadores para reclamar por mayor protección ante la desocupación (Hora, "La política económica" 167-168). Más tarde, Frers recordaba en la CR-1907 la necesidad de resguardar el trabajo femenino en las fábricas textiles, aun cuando otros, como Zuberbühler, las consideraban como "talleres artificiales que sobrevivían por el proteccionismo" (CR-1907, Acta N 5).

\section{d. El impacto en el consumo}

El consumo, en expansión y diversificación en particular en el área de Buenos Aires y sus alrededores a finales del siglo XIX (Rocchi, "Consumir"), fue un aspecto tenido en cuenta por las Comisiones Revisoras al discutir sobre los aforos y los aranceles. Dos cuestiones vinculadas a este tema formaron parte de los debates. Por un lado, se trató el impacto del nivel tarifario en artículos sensibles para el costo de vida de la población en general, en especial de los sectores pobres o desfavorecidos. Por el otro, existieron polémicas en torno al nivel tarifario de artículos considerados "de lujo" o cuyos destinatarios tenían una posición socio-económica acomodada.

En el primer caso, una de las discusiones en la CR-1894 fue si incluir o no a las medias entre los tejidos de punto. Hasta el momento pagaban $40 \%$ ad valorem, es decir, incluirlas significaba aumentar su arancel. Entonces, hubo contraposiciones entre quienes defendían que era un producto de primera necesidad usado por obreros y peones, como Hansen y Kohn, y los que estimaban que las medias tenían el mismo trabajo que las camisetas y que debían pagar arancel más alto, como Cayol (CR-1894, Actas No 3 y 4). En la misma CR1894 se analizó si rebajar a la mitad los aforos para los sombreros ordinarios, ampliamente consumidos por los trabajadores (CR-1894, Acta $\mathrm{N}^{0}$ 6). Por su parte, Videla pensaba que una baja en el arancel de los hilos para máquinas de 
coser era favorable "a las costureras y a la gente pobre" (CR-1894, Acta No 28). La Subcomisión de Comestibles apuntó varias rebajas de bienes consumidos por las (denominadas en las fuentes) "clases menesterosas", como el arroz (CR1894 , Actas No 16, 17 y 20) o el café (CR-1894, Acta No 16). En la CR-1907 hubo insistencia en que más del $95 \%$ de los tejidos y las confecciones era consumido por obreros, de manera que los precios oficiales debían reflejar los precios más bajos (CR-1907, Actas No 3 y 4). En esta Comisión Revisora hubo un interesante debate entre Frers, quien presentó un proyecto para bajar los aforos y derechos de artículos de primera necesidad (comestibles, vestidos, confecciones, calzado, etc.), y Latzina, quien insistía en que lo que encarecía el costo de vida de los obreros eran los alquileres, el pan, la carne y la leche, ya que este grupo gastaba poco en indumentaria, calzados y sombreros importados. Como bajar los niveles arancelarios en bienes de consumo podía traer consecuencias fiscales en el largo plazo, otros integrantes de la CR-1907, como Lahitte, apoyaron la última posición (CR-1907, Acta No 23).

Sobre el segundo tema, las Comisiones Revisoras hicieron hincapié en distinguir aquellos bienes considerados suntuarios. En la CR-1894 existió un acuerdo generalizado en que los productos de talabartería -que incluían carruajes, arreos y monturas- o los mueblesdelicados, podían soportar aforos y derechos altos, pues los fletes que pagaban ya eran de por sí caros y estaban orientados al consumo refinado (CR-1894, Actas $\mathrm{N}^{\mathrm{o}} 7,8$ y 9). Por su parte, Hansen expresó que las lanchas a vapor eran para recreo y que eran "carruajes de los canales del Tigre", de manera que debían tributar (CR-1894, Actas N ${ }^{\circ}$ 12, 13 y 17). Asimismo, la Subcomisión de Comestibles propuso elevar los aranceles de comestibles lujosos, como las trufas (CR-1894, Actas $\mathrm{N}^{\mathrm{o}} 16,17$ y 20), o de artículos presentados en determinadas condiciones, como la sal en tarros de vidrio (CR-1894, Acta No 19). En la CR-1899 se insistió en que existían artículos que, aunque aumentaran, seguirían siendo consumidos, como el ajenjo o los maquillajes (CR-1899, Acta $\mathrm{N}^{\circ} 26$ ). También hubo polémica sobre el aforo de lanas tipo merino para chalones, distintas de las ordinarias para frazadas (CR1899, Acta No 13). Ya en la CR-1907 la Subcomisión de Talabartería reclamó que el automóvil tuviera aforos y derechos bajos, siendo perjudicial para el carruaje a sangre (CR-1907, Acta $\mathrm{N} \square$ 4).

\section{e. Las relaciones con otros países}

Los vínculos internacionales permearon algunas de las discusiones en las CR. Aunque la tensión entre proteccionismo versus librecambio fue el eje central, otras cuestiones tallaron en las discusiones sobre los aforos y los niveles 
tarifarios. Así, por ejemplo, las CR estuvieron preocupadas por si los aranceles bajos fomentaban el ingreso de armas para ser remitidas a países vecinos (CR1894, Acta No 6; CR-1899, Acta No 15; CR-1907, Acta $N^{\circ}$ 23), en un momento en que el lazo entre soberanía, fronteras y seguridad era relevante en la política exterior (Satas).

Pese a que se trataba de un mundo donde se pregonaron los principios del librecambio, las medidas proteccionistas se expandieron en socios comerciales de la Argentina, particularmente en Estados Unidos y en Europa continental (Foreman-Peck 147-152; O'Rourke). En este sentido, los terratenientes sospecharon que los países compradores de las exportaciones agropecuarias tomaran represalias ante la imposición de altas tarifas al ingreso de sus bienes (Vázquez Presedo 215). Esta desconfianza se filtró hacia pequeños agricultores y grupos urbanos, que dependieron directa o indirectamente del sector exportador (Hora, Los terratenientes 161-164).

El temor a las represalias de los socios comerciales circuló durante las discusiones de la CR-1894 sobre los aranceles a la graduación alcohólica -en perjuicio de los vinos italianos y particularmente españoles (CR-1894, Acta $\mathrm{N}^{\mathrm{o}}$ 19). El ministro de Paraguay reclamó un derecho prudencial para la yerba de su país, en comparación con la brasilera, bajo amenaza de reconsiderar el ingreso de productos argentinos a su país (CR-1894, Acta $\mathrm{N}^{\circ} 18$ ). También la CR-1894 tuvo en cuenta el principio de Nación Más Favorecida para no beneficiar injustamente a Estados Unidos con los aranceles a sus sillas de madera. Asimismo, la Subcomisión de Comestibles denunció que el Tratado de Brasil con Estados Unidos ponía en desventaja a las exportaciones argentinas en el país vecino, alterando el acuerdo que regía entre ambos países sudamericanos desde 1856 (CR-1894, Actas $\mathrm{N}^{\circ} 16,17$ y 20). Pese a que no era el principal partenaire comercial, por su postura proteccionista, Estados Unidos fue uno de los socios con los que hubo mayores problemas en materia tarifaria. De hecho, los reclamos argentinos por los aranceles norteamericanos databan de la década de 1860, pero recrudecieron en el último decenio del siglo XIX, cuando se reabrieron las negociaciones diplomáticas sobre la materia (Peterson 267273). Por su parte, la CR-1899 consideró la posibilidad de que Uruguay tomara medidas en contra de artículos argentinos si aumentaban los aranceles de los adoquines -generando controversias con las canteras cordobesas y tandilenses (CR-1899, Acta No 24). En la CR-1907, Pillado alertó sobre la necesidad de cuidar los vínculos con Brasil por la represalia a las harinas (CR-1907, Acta $\mathrm{N}^{\circ}$ 6). Hubo temor a pleitos comerciales si aumentaba el aforo del tabaco habano (CR-1907, Acta Nº 30). Frers temía represalias del gobierno inglés sobre la carne argentina si se arancelaba la entrada de animales en pie (CR-1907, Acta No 24). 
Además, a esa CR llegó un memorándum del ministro de ese país alertando sobre aforos que perjudicaban artículos de su nacionalidad, como los sombreros adornados (CR-1907, Acta $\left.N^{\circ} 10\right)$.

\section{EFECTO DE LAS PROPOSICIONES DE LAS COMISIONES REVISORAS SOBRE LAS LEYES ADUANERAS Y LA POLÍTICA ARANCELARIA ARGENTINA}

Pese a la intención reiterada de los gobiernos, las Comisiones Revisoras no se convirtieron en cuerpos estables, posiblemente por la escasez de recursos humanos y materiales de los que ya hemos hablado. En efecto, esa fue la razón por la que se llamaron en tres oportunidades en algo más de una década. Sin embargo, ¿qué efectos concretos tuvieron en la sanción de las leyes aduaneras posteriores? Una vez que presentaron sus informes, los mismos fueron remitidos por el Poder Ejecutivo al Congreso para ser considerados en las subsiguientes leyes aduaneras. Hasta donde conocemos, solo en 1894 el Ministerio de Hacienda hizo observaciones a la propuesta, ${ }^{8}$ las que fueron tenidas en cuenta por el Poder Legislativo en la sanción de la Ley de Aduanas para 1895. En el apéndice a este trabajo reconstruimos esquemáticamente las principales recomendaciones de las distintas Comisiones en relación a las leyes aduaneras vigentes y su aplicación (o no) en las normas posteriores.

La CR-1894 recomendó bajar las tasas máximas arancelarias en la mayoría de los grupos de productos importados (entre otros, cueros, talabartería, zapatería, confecciones, tejidos, mueblería, etc.), solo dejó sin modificaciones unos pocos, cuyo valor aportado era menor (cristales e instrumentos musicales), subió los aranceles en las materias primas (debido a que muchas pagaban muy bajos derechos o entraban libres) y en bienes de consumo suntuario (como alhajas y relojes), y propuso la eliminación de algunos artículos exentos de impuestos. Asimismo, la CR-1894 respetó la existencia de derechos específicos -en algunos casos los rebajó- y no alteró las disposiciones sobre las exportaciones. En la ley

Entre las principales modificaciones planteadas por el Poder Ejecutivo a la propuesta de la CR1894 estuvieron las siguientes: a) Mantener la tasas del 50\% sobre el calzado porque aún era una industria débil; b) Incrementar de 30\% a 35\% el gravamen sobre los tejidos de seda ya que sus consumidores lo podían costear; c) Establecer un impuesto de diez centavos por kilogramo de aceite vegetal industrial para incentivar el cultivo de plantas oleaginosas; d) Restablecer el impuesto actual para la arpillera dada la baja de los precios de cereales; e) Mantener los niveles vigentes sobre los útiles de labranza para favorecer a la agricultura local y a la industria norteamericana, puesto que Estados Unidos había liberado el ingreso de lanas argentinas y f) No suprimir el impuesto adicional del 1\% porque implicaba renunciar a $\$$ oro 700.000 . 
de Aduanas para 1895 se bajaron aquellos aranceles ad valorem por encima del $50 \%$, se suprimieron algunos bienes libres y se modificaron ciertos aranceles específicos, pero los resultados globales fueron menos rupturistas que las propuestas de la CR-1894.

A diferencia de su predecesora, la CR-1899 no alteró los niveles máximos tarifarios en cada grupo de bienes, pero sí introdujo a muchos en el nivel estándar del 25\% ad valorem, dada la diversidad creciente de artículos cuyo consumo no resistía aranceles mayores. En general, tanto en su labor, como en la ley de Aduanas para 1900, se advierte la complejización en el registro de importaciones debido a la llegada de partidas variadas. Este proceso se intensificó en la CR1907, cuyo principal cambio consistía en convertir los derechos específicos en ad valorem, además de proponer la suba de los niveles máximos en algunos rubros (entre otros, zapatería, confecciones y tejidos) y la eliminación de ítems que ingresaban libres de impuestos. Esta fue la Comisión Revisora que menos efecto tuvo, ya que la ley de Aduanas de 1905 se continuó replicando sin modificaciones hasta 1920 .

\section{REFLEXIONES FINALES}

Como se puede observar, las Comisiones Revisoras no transformaron significativamente el rumbo de la política arancelaria argentina de la época. Sin embargo, consideramos que su estudio es relevante por cuanto fueron reflejo de la diversidad de intereses sobre la materia. Estos cuerpos observaron más aspectos que el nivel tarifario. Su composición fue relativamente variada y participaron de sus debates actores con ideas, orígenes, y expectativas disímiles. En efecto, aunque algunos de sus miembros suscribieron abiertamente al librecambio, a la hora de concluir sobre los distintos grupos de productos, respondieron a cierto pragmatismo dadas las necesidades fiscales y de protección de los sectores geográficos y económicos más débiles. En todas las discusiones quedó en claro la relevancia de los impuestos al comercio exterior como fuente de ingresos de un estado en expansión, de manera que el fiscalismo talló en los intercambios de opiniones. Asimismo, la puja entre el librecambio y el proteccionismo estuvo presente y la inclinación por una u otra dependió del sector que se estuviera negociando, más allá de que en términos relativos y comparativos, el caso argentino exhibiera altos aranceles en general para los artículos comprados en el extranjero. Así, por un lado, se observó cierta predisposición a la liberalización, más en las exportaciones que en las importaciones, pero también en este sector, ya que se tendieron a moderar los aranceles nominales, evitando los extremos de 
gravámenes altos o productos totalmente libres. Además, es importante destacar que el proteccionismo fue planteado como una herramienta para alentar no solo las agro-industrias de las economías regionales, sino también las del litoral -en particular de Buenos Aires y alrededores- que lograban paulatinamente cierto proceso sustitutivo de las importaciones.

Desde luego, este artículo no zanja el debate sobre los niveles ni acerca de la naturaleza de la protección arancelaria durante la economía agroexportadora, problemas para los que consideramos que faltan estudios sectoriales, sino que aporta para pensar en la complejidad del tema y para matizar las "etiquetas", al mostrar la búsqueda del difícil equilibrio en la materia. Varios ejes atravesaron las discusiones, más allá de la producción doméstica y el comercio exterior. También el consumo, el trabajo, las relaciones exteriores y los recursos estatales complejizaron un panorama más variopinto que, como generalmente se ha retratado, dicotómico.

En este sentido, concluimos que, pese a que existen variados e importantes análisis sobre la política comercial argentina en general, y la arancelaria en particular, lo cierto es que no solo escasean en muchos de ellos las referencias a este tipo de instancias de discusión, como las CR que aquí tratamos, sino que mayormente anclan en valores oficiales de los avalúos que dan una referencia nominal de las barreras arancelarias pero que, a falta de actualizaciones periódicas, no representan los precios corrientes de los mercados de la época. Así, insistimos en la necesidad de nuevos aportes basados en evidencia empírica sólida, lo que, dada la diversidad de productos, y tal como vimos en los debates que aquí hemos recreado, posiblemente se alcance con mayor éxito a través de estudios sectoriales.

\section{REFERENCIAS BIBLIOGRÁFICAS}

Alvarez, Juan. Temas de historia económica argentina. El Ateneo, 1929.

Balán, Jorge. "Una cuestión regional en la Argentina: Burguesías provinciales y el mercado nacional en el desarrollo agroexportador". Desarrollo Económico, 18, no. 69, 1978, pp. 49-87.https://doi.org/10.2307/3466376

Belini, Claudio. Historia de la industria en la Argentina. De la Independencia a la crisis de 2001. Sudamericana, 2017.

Bolt, Jutta, et al. Rebasing "Maddison”: New Income Comparisons and the Shape if Long-Run Economic Development. GGDC Research Memorandum. Groningen Growth and Development Centre, 2018.

Caravaca, Jimena. ¿Liberalismo o Intervencionismo? Debates sobre el rol del Estado en la economía argentina, 1870-1935. Sudamericana, 2011. 
Chiaramonte, José Carlos. Nacionalismo y liberalismo económicos en Argentina, 1860-1880. Edhasa, 2012.

Clemens, Michael A. y Jeffrey G. Williamson. "Why were Latin America's Tariffs so much Higher than Asia's before 1950?". Revista de Historia Económica/Journal pf Iberian and Latin American Economic History, 30, no. 1, 2011, pp. 11-44.https://doi.org/10.1017/S021261091100019X

Coatsworth, John H. y Jeffrey G. Williamson. "Always Proteccionist? Latin American Tariffs from Independence to Great Depression". Journal of Latin American Studies, vol. 36, no. 2, 2004, pp. 205-232. https://doi.org/10.1017/S0022216X04007412

Cortés Conde, Roberto. "Argentina. Las vicisitudes de una economía exportadora". La era de las exportaciones latinoamericanas. De fines del siglo XIX a principios del siglo XX, compilado por Enrique Cárdenas, José Antonio Ocampo y Rosemary Thorp, Fondo de Cultura Económica, 2003, pp. 360-417.

- La economía argentina en el largo plazo (siglos XIX y XX). SudamericanaUDESA, 1997.

Cucchi, Laura y Inés Rojkind. "Presentación de dossier. Oligarquía, república y democracia: Debates sobre la vida política en la Argentina del orden conservador". Investigaciones y Ensayos, no. 65, 2017, pp. 29-34.

DellaPaolera, Gerardo y Alan Taylor. Tensando el ancla. La Caja de Conversión argentina y la búsqueda de la estabilidad macroeconómica, 1880-1935. Fondo de Cultura Económica, 2003.

Díaz Alejandro, Carlos F. Ensayos sobre la historia económica argentina. Amorrortu, 2002.

Federico, Giovanni y Antonio Tena. "On the Accuracy of Foreign Trade Statistics (1909-1935)". Explorations in Economic History, no. 28, 1991, pp. 259273.https://doi.org/10.1016/0014-4983(91)90007-6

Fernández, Alejandro. Las exportaciones españolas a la argentina: un enfoque comparativo (1880-1935). Universidad de Barcelona, 2001.

Ferreres, Orlando. Dos siglos de economía argentina (1810-2010). Historia argentina en cifras. El Ateneo, 2005.

Foreman-Peck, James. Historia económica mundial. Relaciones económicas internacionales desde 1850. Ariel, 1995.

Gallo, Ezequiel. "Agrarian expansion and industrial development in Argentina (1880-1930)". St. Antony's Papers, 1970, pp. 13-25.

-----. "Un quinquenio difícil: las presidencias de Carlos Pellegrini y Luis Sáenz Peña (1890-1895)". La Argentina del Ochenta al Centenario,compilado por Gustavo Ferrari y Ezequiel Gallo, Sudamericana, 1980, pp. 215-243. 
Geller, Lucio. "El crecimiento industrial argentino hasta 1914 y la teoría del bien primario exportable". El régimen oligárquico: materiales para el estudio de la realidad argentina (hasta 1930), compilado por Marcos Giménez Zapiola, Amorrortu, 1975, pp. 152-200.

Gerchunoff, Pablo y Lucas Llach. El ciclo de la ilusión y el desencanto. Un siglo de políticas económicas argentinas. Emecé, 2007.

Gerchunoff, Pablo, Fernando Rocchi y Gastón Rossi. Desorden y progreso. Las crisis económicas argentinas, 1870-1905. Edhasa, 2008.

González Bollo, Hernán. La fábrica de las cifras oficiales del Estado argentino (1869-1947). Universidad Nacional de Quilmes, 2014.

Guy, Donna. "Carlos Pellegrini and the Politics of Early Industrialization, 18731906". Journal of Latin American Studies, vol. 11, no. 1, 1979, pp. 123144.https://doi.org/10.1017/S0022216X0002232X

Harriague, María Marcela y Agustina Rayes. "Fuentes para el estudio de la historia económica argentina". Nueva historia económica de la Argentina, dirigido por Roberto Cortés Conde y Gerardo DellaPaolera, Edhasa, 2018, pp. 243-275.

Hora, Roy. "La política económica del proteccionismo en la Argentina, 18701914”. Investigaciones y Ensayos, 58, 2009, pp. 237-283.

-----. Los terratenientes de la Pampa argentina. Una historia social y política. Siglo XXI Editores, 2015.

Kuntz-Ficker, Sandra y Agustina Rayes. "The contribution of Argentine Exports to the Economy, 1875-1929". The First Export Era Revisited: Reassessing its Economic Contribution to Latin American Economies, editado por Sandra Kuntz-Ficker, Palgrave-Macmillan, 2017, pp. 37-72. https://doi.org/10.1007/978-3-319-62340-5_2

Moyano, Daniel. "El alcohol de melaza. Análisis sobre el desarrollo y consolidación de una actividad 'derivada' de la agroindustria azucarera tucumana (1880-1910)”. H-Industri@. Revista de historia de la industria, los servicios y las empresas en América Latina, 13, 2013, pp. 1-35.

O'Rourke, Kevin H. “The European Grain Invasion, 1870-1913”. The Journal of Economic History, 57, no. 4, 1997, pp. 775-801.

Pessagno, Atilio. Legislación fiscal y tramitación aduanera. Buenos Aires, 1911. Peterson, Harold. La Argentina y los Estados Unidos. I. 1810-1914. Hyspamerica, 1985.

Rayes, Agustina. "La estadística de las exportaciones argentinas, 1875-1913. Nuevas evidencias e interpretaciones". Investigaciones de Historia Económica, vol. 11, no. 1, 2015, pp. 31-42.https://doi.org/10.1016/j. ihe.2014.03.015 
-----. "The Other Side of Argentine Foreign Trade: Sources for the Study of Imports, 1880-1913". Revista de Historia Económica - Journal of Iberian and Latin American Economic History, vol. 36, no. 1, 2018, pp. 27-51. https://doi.org/10.1017/S0212610917000155

-----. "The Trade Policy of Argentina, 1870-1913. A Study through Customs Legislation". Workshop. AustralianNationalUniversity, 2018, pp. 1-30.

Rayes, Agustina, Rodrigo Castro y Francisco Ibarra. "Números oscuros. La valoración de las importaciones argentinas, c. 1870-1913". Revista Uruguaya de Historia Económica, vol. 17, 2020, pp. 25-48. https://doi.org/10.47003/ruhe/10.17.02

Regalsky, Andrés. "Los comienzos de la industrialización en Argentina, 18801930". Revista Digital de la Facultad de Arte y Humanidades de la UNR, no. 2, 2011, pp. 75-106.

Rocchi, Fernando. Chimneys in the Desert. Industrialization in Argentina during the Export Boom Years, 1870-1930. Stanford UniversityPress, 2006.

-----. "Consumir es un placer: la industria y la expansión de la demanda en Buenos Aires a la vuelta del siglo pasado". Desarrollo Económico, vol. 37, no. 148, 1998, pp. 533-558.https://doi.org/10.2307/3467411

-----. "El imperio del pragmatismo: intereses, ideas e imágenes de la política industrial durante el orden conservador". Anuario IEHS, no. 13, 1998, pp. 99-130.

Rosiello, Juan Carlos. Controversias sobre la política comercial en la Argentina, 1877-1913. PhD Tesis, Buenos Aires, ESEADE, 2011.

Sánchez Román, José Antonio. Los argentinos y los impuestos. Lazos frágiles entre sociedad y fisco en el siglo XX. Siglo XXI Editores, 2013.

Satas, Hugo. Una política exterior argentina. Hyspamerica, 1987.

Vázquez Presedo, Vicente. El caso argentino: migración de factores, comercio exterior y desarrollo, 1875-1914. Editorial Universitaria de Buenos Aires, 1979.

Winograd, Carlos y Marie Véganzones. Argentina en el siglo XX: crónica de un crecimiento anunciado. Organización para la Cooperación y el Desarrollo Económico, 1997.

Zimmermann, Eduardo. Los liberales reformistas. La cuestión social en la Argentina 1890-1916. Sudamericana, 1995. 


\section{FUENTES PRIMARIAS}

Carta de Emilio Frers, Presidente de la CR-1907, al Ministro de Hacienda, Eleodoro Lobos, Buenos Aires, 18/06/1907.

Carta de J. Figueroa Alcorta y E. Lobos al Congreso Nacional, Buenos Aires, 26 de junio de 1907.

Carta de la CR-1894 al Ministerio de Hacienda, Buenos Aires, 16/04/1894.

Carta de Presidente de CR-1907, Emilio Frers, al Ministro de Hacienda, Manuel de Iriondo, Buenos Aires, 19/11/1907.

Carta del Presidente de CR-1894, Lorenzo Anadón, al Ministro de Hacienda, José Terry, Buenos Aires, 20/09/1894.

Carta del Presidente de la CR-1899, Lorenzo Anadón, a Ministerio de Hacienda, Buenos Aires, 15/01/1900.

Decreto presidencial, Buenos Aires, 29/07/1899.

Dirección General de Estadística de la Nación. Anuarios de comercio exterior, Buenos Aires, Compañía de Billetes Sudamericana, varios años (1870-1913).

Dirección General de Comercio e Industria. Anuario. Nociones útiles, Buenos Aires, 1927.

Latzina, F. (1886). Proyecto de Reforma de la Tarifa de Avalúos vigente y conversión de los actuales derechos ad valorem en especificos sobre la base de la equivalencia de unos y otros. Buenos Aires: Stiller y Laass.

Ley de Aduana de 1923, Buenos Aires, 29/11/1923.

Ley del Presupuesto General de la República Argentina para el ejercicio de 1890 (ley número 2697), Buenos Aires, 28/12/1889, art. 3.

Ley del Presupuesto General de la República Argentina para el ejercicio de 1891 (ley número 2747), Buenos Aires, 13/10/1890, art. 1.

Pessagno, A. (1911). Legislación fiscal y tramitación aduanera, Buenos Aires. Poder Ejecutivo. Tarifas de Aduana. Estudios y antecedentes para su discusión legislativa por la Comisión Revisora nombrada por el Poder Ejecutivo, Buenos Aires, Compañía Sudamericana de Billetes de Banco, 1894.

-----. Tarifas de Aduana. Estudios y antecedentes para su discusión legislativa por la Comisión Revisora nombrada por el Poder Ejecutivo, Buenos Aires, Compañía Sudamericana de Billetes de Banco, 1900.

-----. Comisión Revisora de las Leyes Aduaneras. Estudios e Informes. I Parte.

Proyecto de reformas a la Tarifa de Avalúos para 1908, Buenos Aires,

Casa Editora e Impresora M. Rodríguez Giles, 1907.

-----. Comisión Revisora de las Leyes Aduaneras. Estudios e Informes. II Parte.

Proyecto de reformas a la Ley de Aduanas para 1908, Buenos Aires,

Casa Editora e Impresora M. Rodríguez Giles, 1907.

Poder Legislativo. Leyes de Aduanas. Buenos Aires, varios años (1870-1923). 
CR-1894, Acta No 1, Buenos Aires, 07/08/1894. CR-1894, Acta No 2, Buenos Aires, 08/08/1894. CR-1894, Acta No 3, Buenos Aires, 09/08/1894. CR-1894, Acta No 4, Buenos Aires, 10/08/1894. CR-1894, Acta No 5, Buenos Aires, 11/08/1894. CR-1894, Acta No 6, Buenos Aires, 14/08/1894. CR-1894, Acta No 7 , Buenos Aires, 16/08/1894. CR-1894, Acta No 8, Buenos Aires, 17/08/1894. CR-1894, Acta No 9, Buenos Aires, 18/08/1894. CR-1894, Acta No 11, Buenos Aires, 21/08/1894. CR-1894, Acta No 12, Buenos Aires, 22/08/1894. CR-1894, Acta No 13, Buenos Aires, 23/08/1894. CR-1894, Acta No 15, Buenos Aires, 27/08/1894. CR-1894, Acta No 16, Buenos Aires, 28/08/1894. CR-1894, Acta No 17, Buenos Aires, 29/08/1894. CR-1894, Acta No 18, Buenos Aires, 31/08/1894. CR-1894, Acta No 19, Buenos Aires, 01/09/1894. CR-1894, Acta No 20, Buenos Aires, 03/09/1894. CR-1894, Acta No 21, Buenos Aires, 4/09/1894. CR-1894, Acta No 22, Buenos Aires, 05/09/1894. CR-1894, Acta No 23, Buenos Aires, 6/09/1894. CR-1894, Acta No 24, Buenos Aires, 07/09/1894. CR-1894, Acta No 25, Buenos Aires, 10/09/1894. CR-1894, Acta No 26, Buenos Aires, 11/09/1894. CR-1894, Acta No 27, Buenos Aires, 12/09/1894. CR-1894, Acta No 28, Buenos Aires, 14/09/1894. CR-1894, Acta No 29, Buenos Aires, 15/09/1894. CR-1894, Acta No 30, Buenos Aires, 18/09/1894.

CR-1899, Acta No 1, Buenos Aires, 25/07/1899. CR-1899, Acta No 2, Buenos Aires, 27/07/1899. CR-1899, Acta No 5, Buenos Aires, 07/09/1899. CR-1899, Acta No 6, Buenos Aires, 12/09/1899. CR-1899, Acta No 7, Buenos Aires, 09/10/1899. CR-1899, Acta No 8, Buenos Aires, 12/10/1899. CR-1899, Acta No 9, Buenos Aires, 17/10/1899. CR-1899, Acta No 10, Buenos Aires, 19/10/1899. CR-1899, Acta No 11, Buenos Aires, 21/10/1899. CR-1899, Acta No 12, Buenos Aires, 24/10/1899. 
CR-1899, Acta No 13, Buenos Aires, 16/10/1899. CR-1899, Acta No 14, Buenos Aires, 31/10/1899. CR-1899, Acta No 15, Buenos Aires, 02/11/1899. CR-1899, Acta No 16, Buenos Aires, 03/11/1899. CR-1899, Acta No 17, Buenos Aires, 06/11/1899. CR-1899, Acta No 18, Buenos Aires, 07/11/1899. CR-1899, Acta No 20, Buenos Aires, 13/11/1899. CR-1899, Acta No 22, Buenos Aires, 16/11/1899. CR-1899, Acta No 23, Buenos Aires, 17/11/1899. CR-1899, Acta No 24, Buenos Aires, 18/11/1899. CR-1899, Acta No 26, Buenos Aires, 21/11/1899. CR-1899, Acta No 27, Buenos Aires, 22/11/1899. CR-1899, Acta No 29, Buenos Aires, 25/11/1899. CR-1899, Acta No 31, Buenos Aires, 05/12/1899.

CR-1907, Acta No 1, Buenos Aires, 18/02/1907. CR-1907, Acta No 2, Buenos Aires, 06/03/1907. CR-1907, Acta No 3, Buenos Aires, 17/04/1907. CR-1907, Acta No 4, Buenos Aires, 16/05/1907. CR-1907, Acta No 5, Buenos Aires, 18/05/1907. CR-1907, Acta No 6, Buenos Aires, 20/05/1907. CR-1907, Acta No 7, Buenos Aires, 13/04/1907. CR-1907, Acta No 8, Buenos Aires, 23/05/1907. CR-1907, Acta No 9, Buenos Aires, 24/05/1907. CR-1907, Acta No 10, Buenos Aires, 30/05/1907. CR-1907, Acta No 11, Buenos Aires, 05/06/1907. CR-1907, Acta No 12, Buenos Aires, 07/06/1907. CR-1907, Acta No 13, Buenos Aires, 08/06/1907. CR-1907, Acta No 14, Buenos Aires, 10/06/1907. CR-1907, Acta No 15, Buenos Aires, 15/05/1907. CR-1907, Acta No 16, Buenos Aires, 03/07/1907. CR-1907, Acta No 23, Buenos Aires, 24/08/1907. CR-1907, Acta No 24, Buenos Aires, 09/09/1907. CR-1907, Acta No 30, Buenos Aires, 21/09/1907. 


\section{Apéndice}

Tabla 1: Análisis CR-1894 (aranceles vigentes, propuesta y ley posterior)

\begin{tabular}{|c|c|c|c|}
\hline $\begin{array}{l}\text { Categoría de } \\
\text { productos }\end{array}$ & $\begin{array}{l}\text { Arancel vigente } \\
\text { Ley de Aduana } \\
1894\end{array}$ & $\begin{array}{l}\text { Arancel sugerido } \\
\text { por CR-1894 }\end{array}$ & $\begin{array}{l}\text { Arancel votado en } \\
\text { Ley de Aduana de } \\
1895\end{array}$ \\
\hline Cueros y pieles & $40 \%$ & $35 \%$ & $40 \%$ \\
\hline Talabartería & $25 \%$ y $60 \%$ & $25 \%$ y $50 \%$ & $25 \%$ y $50 \%$ \\
\hline Zapatería & $25 \%$ y $60 \%$ & $25 \%$ y $40 \%$ & $25 \%$ y $50 \%$ \\
\hline $\begin{array}{l}\text { Confecciones y } \\
\text { ropa hecha }\end{array}$ & $60 \%$ & $45 \%$ у $50 \%$ & $40 \%$ у $50 \%$ \\
\hline Tejidos & $5 \%, 25 \%, 40 \%$ у $60 \%$ & $20 \%, 25 \%$ y $30 \%$ & $\begin{array}{l}5 \%, 15 \%, 20 \%, 25 \%, \\
40 \%, 45 \%, 50 \% \text { y } \\
\text { específicos (fieltros } \\
\text { adherentes para } \\
\text { sombreros de hombre } \\
\$ 0,35 / \mathrm{kg} .)\end{array}$ \\
\hline $\begin{array}{l}\text { Artículos e } \\
\text { instrumentos de } \\
\text { música }\end{array}$ & $25 \%$ & $25 \%$ & $25 \%$ \\
\hline Armería & $50 \%$ & $25 \%$ y $50 \%$ & $50 \%$ \\
\hline Alhajas y relojes & $5 \%$ y $25 \%$ & $10 \%$ y $25 \%$ & $5 \%$ y $25 \%$ \\
\hline Sombrerería & $\begin{array}{l}25 \%, 60 \% \text { y específicos } \\
\text { (\$0,5 c/u de lana y } \\
\$ 2,5 \text { c/u de copa alta) }\end{array}$ & $\begin{array}{l}25 \%, 50 \% \text { y } \\
\text { específicos }(\$ 0,4 \text { de } \\
\text { lana y } \$ 2 \text { de copa alta) }\end{array}$ & $\begin{array}{l}25 \%, 50 \% \text { y } \\
\text { específicos }(\$ 0,4 \text { de } \\
\text { lana y } \$ 2 \text { copa alta) }\end{array}$ \\
\hline Mueblería & $60 \%$ & $50 \%$ & $50 \%$ \\
\hline $\begin{array}{l}\text { Ferretería y } \\
\text { artículos navales }\end{array}$ & $\begin{array}{l}\text { libres, } 5 \%, 25 \%, \\
40 \%, 50 \%, 60 \% \text { y } \\
\text { específicos (tirantes de } \\
\text { fierro, caños, puntas } \\
\text { de París y papel lija) }\end{array}$ & libres, $10 \%, 25 \%$ & $5 \%, 10 \%, 25 \%$ y $40 \%$ \\
\hline Comestibles & $\begin{array}{l}25 \%, 50 \% \text {, libres y } \\
\text { específicos }\end{array}$ & $\begin{array}{l}25 \%, 50 \% \text {, libres } \\
\text { (harina de trigo o } \\
\text { maíz, caña de azúcar) } \\
\text { y específicos (arroz } \\
\$ 0,015 / \mathrm{kg} ., \text { azúcar } \\
\text { refinada } \$ 0,09 / \mathrm{kg} . \text {, } \\
\text { café en grano } \$ 0,05 / \\
\mathrm{kg.,} \mathrm{té} \$ 0,2 / \mathrm{kg} \text {. y yerba } \\
\text { paraguaya } \$ 0,05 / \mathrm{kg} . \text {.) }\end{array}$ & $\begin{array}{l}10 \%, 25 \% \text {, libres } \\
\text { (harina de trigo o } \\
\text { maíz, caña de azúcar) } \\
\text { y específicos (arroz } \\
\$ 0,02 / \mathrm{kg} ., \text { azúcar } \\
\text { refinada } \$ 0,09 / \mathrm{kg} ., \\
\text { café en grano } \$ 0,05 / \\
\text { kg., té } \$ 0,2 / \mathrm{kg} . \text { y yerba } \\
\text { paraguaya } \$ 0,05 / \mathrm{kg} . \text { ) }\end{array}$ \\
\hline
\end{tabular}


(continuación) Análisis CR-1894

\begin{tabular}{|c|c|c|c|}
\hline $\begin{array}{l}\text { Categoría de } \\
\text { productos }\end{array}$ & $\begin{array}{l}\text { Arancel vigente } \\
\text { Ley de Aduana } \\
1894\end{array}$ & $\begin{array}{l}\text { Arancel sugerido } \\
\text { por CR-1894 }\end{array}$ & $\begin{array}{l}\text { Arancel votado en } \\
\text { Ley de Aduana de } \\
1895\end{array}$ \\
\hline Bebidas & específicos & $\begin{array}{l}\text { específicos (cerveza } \\
\text { embotellada } \$ 0,12 / \\
\text { botella y vinos } \\
\text { comunes de no más } \\
\text { de } 18 \text { grados de fuerza } \\
\text { alcohólica y } 50 \% \text { de } \\
\text { extracto seco a } \$ 0,08 / \\
\text { lt.) }\end{array}$ & $\begin{array}{l}\text { específicos (cerveza } \\
\text { embotellada } \$ 0,12 / \\
\text { botella y vinos } \\
\text { comunes de no más } \\
\text { de } 17 \text { grados de fuerza } \\
\text { alcohólica y } 50 \% \text { de } \\
\text { extracto seco a } \$ 0,08 / \\
\text { lt.) }\end{array}$ \\
\hline $\begin{array}{l}\text { Mercería y } \\
\text { artículos de bazar } \\
\text { y de fantasía }\end{array}$ & $\begin{array}{l}5 \%, 25 \%, 40 \%, 60 \% \\
\text { y específicos (papel y } \\
\text { fósforos) }\end{array}$ & $\begin{array}{l}5 \%, 10 \%, 25 \%, 30 \%, \\
50 \% \text { y específicos } \\
\text { (papel de colores } \\
\$ 0,12 / \mathrm{kg} \text {. y papel } \\
\text { blanco para diarios } \\
\$ 0,03 / \mathrm{kg} . \text { ) }\end{array}$ & $\begin{array}{l}5 \%, 25 \% \text { y específicos } \\
\text { (papel de colores } \\
\$ 0,12 / \mathrm{kg} . \text { y papel } \\
\text { blanco para diarios } \\
\$ 0,03 / \mathrm{kg} . \text { ) }\end{array}$ \\
\hline $\begin{array}{l}\text { Lamparería y } \\
\text { artículos de } \\
\text { iluminación }\end{array}$ & $\begin{array}{l}25 \% \text { y específicos } \\
\text { (fósforos de cera } \\
\text { sueltos a } \$ 0,8 / \mathrm{kg} \text { ) }\end{array}$ & $\begin{array}{l}10 \%, 25 \%, 30 \% \text { y } \\
\text { específicos (fósforos } \\
\text { de palo sueltos a } \$ 0,4 / \\
\mathrm{kg} ., \text { fósforos de cera } \\
\text { sueltos a } \$ 1,6 / \mathrm{kg} \text { ) }\end{array}$ & $\begin{array}{l}10 \%, 25 \% \text { y } \\
\text { específicos (fósforo s } \\
\text { de palo sueltos a } \$ 0,4 / \\
\mathrm{kg} ., \text { fósforos de cera } \\
\text { sueltos a } \$ 1,6 / \mathrm{kg} \text { ) }\end{array}$ \\
\hline $\begin{array}{l}\text { Cerámica y } \\
\text { cristales }\end{array}$ & $25 \%$ & $25 \%$ & $25 \%$ \\
\hline $\begin{array}{l}\text { Droguería, } \\
\text { productos } \\
\text { químicos, útiles y } \\
\text { accesorios }\end{array}$ & $\begin{array}{l}\text { libres, } 5 \%, 25 \%, 40 \% \\
\text { y específicos (aceites } \\
\text { vegetales } \$ 0,12 / 1 \mathrm{t} .)\end{array}$ & $\begin{array}{l}\text { libres, } 2,5 \%, 5 \%, 10 \% \text {, } \\
25 \% \text { y específicos } \\
\text { (aceites vegetales } \\
\$ 0,05 / \text { lt.) }\end{array}$ & $\begin{array}{l}5 \%, 10 \%, 25 \%, 50 \% \\
\text { y específicos (aceites } \\
\text { vegetales } \$ 0,1 / 1 \mathrm{t} .)\end{array}$ \\
\hline Tabacos & $\begin{array}{l}\text { específicos (cigarros } \\
\text { habanos } \$ 4 / \mathrm{kg} . \text {, } \\
\text { cigarros no habanos } \\
\$ 2 / \mathrm{kg} . \text {, tabaco habano } \\
\text { en hojas } \$ 2 / \mathrm{kg} . \text {, tabaco } \\
\text { habano picadura } \$ 2 / \\
\mathrm{kg} . \text {, tabaco en hoja } \\
\text { o picadura otras } \\
\text { procedencias } \$ 1 / \mathrm{kg} \text {., } \\
\text { tabaco paraguayo } \\
\$ 0,5 / \mathrm{kg} \text {., cigarrillos } \\
\$ 2 / \mathrm{kg} \text {.) }\end{array}$ & $\begin{array}{l}\text { específicos (cigarros } \\
\text { habanos } \$ 4 / \mathrm{kg} ., \\
\text { cigarros no habanos } \\
\$ 0,75 / \mathrm{kg} . \text {, tabaco } \\
\text { habano en hojas } \$ 1 / \\
\text { kg., tabaco habano } \\
\text { picadura } \$ 1 / \mathrm{kg} ., \\
\text { tabaco en hoja } \\
\text { o picadura otras } \\
\text { procedencias } \$ 0,4 / \\
\text { kg., tabaco paraguayo } \\
\$ 0,1 / \mathrm{kg} \text {., cigarrillos } \\
\$ 1 / \mathrm{kg} .)\end{array}$ & $\begin{array}{l}\text { específicos (cigarros } \\
\text { habanos } \$ 3 / \mathrm{kg} ., \\
\text { cigarros no habanos } \\
\$ 1 / \mathrm{kg} . \text { tabaco habano } \\
\text { en hojas } \$ 1 / \mathrm{kg} . \text {, tabaco } \\
\text { habano picadura } \$ 1 / \\
\mathrm{kg} . \text {, tabaco en hoja } \\
\text { o picadura otras } \\
\text { procedencias } \$ 0,4 / \\
\mathrm{kg} . \text { tabaco paraguayo } \\
\$ 0,3 / \mathrm{kg} \text {., cigarrillos } \\
\$ 1 / \mathrm{kg} .)\end{array}$ \\
\hline
\end{tabular}


(continuación) Análisis CR-1894

\begin{tabular}{|c|c|c|c|}
\hline $\begin{array}{l}\text { Categoría de } \\
\text { productos }\end{array}$ & $\begin{array}{l}\text { Arancel vigente } \\
\text { Ley de Aduana } \\
1894\end{array}$ & $\begin{array}{l}\text { Arancel sugerido } \\
\text { por CR-1894 }\end{array}$ & $\begin{array}{l}\text { Arancel votado en } \\
\text { Ley de Aduana de } \\
1895\end{array}$ \\
\hline Varios & $\begin{array}{l}25 \%, 60 \% \text { y } \\
\text { específicos }\end{array}$ & $\begin{array}{l}5 \%, 25 \%, 50 \% \text { y } \\
\text { específicos (cuellos y } \\
\text { puños de algodón } \$ 3 / \\
\text { docena) }\end{array}$ & $\begin{array}{l}5 \%, 25 \%, 40 \% \text { y } \\
\text { específicos (cuellos } \\
\text { de algodón } \$ 1,5 / \text { doc. } \\
\text { y puños de algodón } \\
\$ 2,25 / \text { docena) }\end{array}$ \\
\hline Materias primas & libres & $\begin{array}{l}\text { libres, } 2,5 \%, 5 \% \text { y } \\
10 \%\end{array}$ & libres, $2,5 \%, 5 \%, 15 \%$ \\
\hline Artículos libres & varios & $\begin{array}{l}\text { suprimir arena de } \\
\text { Fontaneibleau, azogue, } \\
\text { barrenos para minas, } \\
\text { carozos de Guayaquil, } \\
\text { corteza de alcornoque, } \\
\text { fulminantes para } \\
\text { dinamita, guías y } \\
\text { mechas para usos } \\
\text { mineros, hierro } \\
\text { viejo, hilados de lana } \\
\text { y algodón, demás } \\
\text { hilados, libros, lúpulo, } \\
\text { máquinas agrícolas, } \\
\text { máquinas para minas, } \\
\text { pasta de madera, pelo } \\
\text { de conejo, pólvora } \\
\text { para minas, semillas } \\
\text { para agricultura. }\end{array}$ & $\begin{array}{l}\text { No suprimió } \\
\text { alcornoque, dinamita } \\
\text { para minas, ni } \\
\text { máquinas para } \\
\text { agricultura }\end{array}$ \\
\hline Exportables & libres, $2 \%, 4 \%$ & $\begin{array}{l}\text { libres, } 2 \%, 4 \% \text { (hierro y } \\
\text { acero viejos a } \$ 10 / \text { tn.) }\end{array}$ & $\begin{array}{l}\text { libres, } 2 \%, 4 \% \text { y } \\
\text { específico (hierro y } \\
\text { acero viejos a } \$ 10 / \mathrm{tn} . \text {.) }\end{array}$ \\
\hline
\end{tabular}

Fuente: Elaboración propia a partir de informes de las Comisiones Revisoras y de leyes aduaneras. 
Tabla 2: Análisis CR-1899 (aranceles vigentes, propuesta y ley posterior)

\begin{tabular}{|c|c|c|c|}
\hline $\begin{array}{l}\text { Categoría de } \\
\text { productos }\end{array}$ & $\begin{array}{l}\text { Arancel vigente } \\
\text { Ley de Aduana } \\
1899\end{array}$ & $\begin{array}{l}\text { Arancel sugerido } \\
\text { por CR-1899 }\end{array}$ & $\begin{array}{l}\text { Arancel votado en } \\
\text { Ley de Aduana de } \\
1900\end{array}$ \\
\hline Cueros y pieles & $40 \%$ & $25 \%$ y $40 \%$ & $40 \%$ \\
\hline Talabartería & $25 \%$ y $50 \%$ & $25 \%$ y $50 \%$ & $25 \%$ y $50 \%$ \\
\hline Zapatería & $25 \%$ y $50 \%$ & $25 \%$ y $50 \%$ & $25 \%$ y $50 \%$ \\
\hline $\begin{array}{l}\text { Confecciones y ropa } \\
\text { hecha }\end{array}$ & $25 \%$ y $50 \%$ & $25 \%$ у $50 \%$ & $25 \%$ у $50 \%$ \\
\hline Tejidos & $\begin{array}{l}4 \%, 5 \%, 10 \%, 15 \%, \\
20 \%, 25 \%, 40 \%, \\
45 \% \text { y específicos } \\
\text { (fieltros adherentes } \\
\text { para sombreros de } \\
\text { hombre } \$ 0,30 / \mathrm{kg} . \text { ) }\end{array}$ & $25 \%, 35 \%$ y $40 \%$ & $\begin{array}{l}5 \%, 10 \%, 15 \%, 20 \%, \\
25 \%, 35 \%, 40 \%, \\
45 \% \text { y específicos } \\
\text { (fieltros adherentes } \\
\text { para sombreros de } \\
\text { hombre } \$ 0,30 / \mathrm{kg} . \text { ) }\end{array}$ \\
\hline $\begin{array}{l}\text { Artículos e } \\
\text { instrumentos de } \\
\text { música } \\
\end{array}$ & $25 \%$ & $25 \%$ & $25 \%$ \\
\hline Armería & $50 \%$ & $25 \%$ y $50 \%$ & $25 \%$ y $50 \%$ \\
\hline Alhajas y relojes & $2,5 \%, 5 \%$ y $25 \%$ & $5 \%$ у $25 \%$ & $5 \%$ y $25 \%$ \\
\hline Sombrerería & $\begin{array}{l}25 \%, 50 \% \text { y } \\
\text { específicos }(\$ 0,4 \text { de } \\
\text { lana y } \$ 2 \text { copa alta })\end{array}$ & $25 \%, 35 \%$ y $50 \%$ & $\begin{array}{l}25 \%, 50 \% \text { y } \\
\text { específicos }(\$ 0,4 \text { de } \\
\text { lana y } \$ 2 \text { copa alta })\end{array}$ \\
\hline Mueblería & $50 \%$ & $25 \%$ у $50 \%$ & $25 \%$ у $50 \%$ \\
\hline $\begin{array}{l}\text { Ferretería y artículos } \\
\text { navales }\end{array}$ & $\begin{array}{l}5 \%, 10 \%, 25 \% y \\
40 \%\end{array}$ & $\begin{array}{l}5 \%, 10 \%, 25 \% y \\
40 \%\end{array}$ & $\begin{array}{l}10 \%, 20 \%, 25 \%, \\
40 \%\end{array}$ \\
\hline Comestibles & $\begin{array}{l}5 \%, 10 \%, 25 \% \text {, libres } \\
\text { (harina de trigo o } \\
\text { maíz, caña de azúcar) } \\
\text { y específicos (arroz } \\
\$ 0,02 / \mathrm{kg} . \text { azúcar } \\
\text { refinada } \$ 0,09 / \mathrm{kg} . \text {, } \\
\text { café en grano } \$ 0,03 / \\
\mathrm{kg} . \text { té } \$ 0,2 / \mathrm{kg} . \text { y } \\
\text { yerba general } \$ 0,04 / \\
\mathrm{kg} . \text {.) }\end{array}$ & $\begin{array}{l}5 \%, 10 \%, 25 \% \text {, libres } \\
\text { (harina de trigo o } \\
\text { maíz, caña de azúcar) } \\
\text { y específicos (arroz } \\
\$ 0,02 / \mathrm{kg} . \text { azúcar } \\
\text { refinada } \$ 0,09 / \mathrm{kg} . \text {, } \\
\text { café en grano } \$ 0,03 / \\
\mathrm{kg} . \text { té } \$ 0,2 / \mathrm{kg} . \text { y } \\
\text { yerba general } \$ 0,04 / \\
\mathrm{kg} . \text { ) }\end{array}$ & $\begin{array}{l}5 \%, 10 \%, 25 \% \text {, libres } \\
\text { (harina de trigo o } \\
\text { maíz, caña de azúcar) } \\
\text { y específicos (arroz } \\
\$ 0,02 / \mathrm{kg} ., \text { azúcar } \\
\text { refinada } \$ 0,09 / \mathrm{kg} . \text {, } \\
\text { café en grano } \$ 0,03 / \\
\mathrm{kg} . \text { té } \$ 0,2 / \mathrm{kg} . \text { y } \\
\text { yerba general } \$ 0,04 / \\
\text { kg.) }\end{array}$ \\
\hline $\begin{array}{l}\text { Categoría de } \\
\text { productos }\end{array}$ & $\begin{array}{l}\text { Arancel vigente Ley } \\
\text { de Aduana } 1899\end{array}$ & $\begin{array}{l}\text { Arancel sugerido por } \\
\text { CR-1899 }\end{array}$ & $\begin{array}{l}\text { Arancel votado en } \\
\text { Ley de Aduana de } \\
1900\end{array}$ \\
\hline
\end{tabular}


(continuación) Análisis CR-1899

\begin{tabular}{|c|c|c|c|}
\hline $\begin{array}{l}\text { Categoría de } \\
\text { productos }\end{array}$ & $\begin{array}{l}\text { Arancel vigente } \\
\text { Ley de Aduana } \\
1899\end{array}$ & $\begin{array}{l}\text { Arancel sugerido } \\
\text { por CR-1899 }\end{array}$ & $\begin{array}{l}\text { Arancel votado en } \\
\text { Ley de Aduana de } \\
1900\end{array}$ \\
\hline Bebidas & $\begin{array}{l}\text { específicos (cerveza } \\
\text { embotellada } \$ 0,12 / \\
\text { botella y vinos } \\
\text { comunes de no más } \\
\text { de } 15 \text { grados de } \\
\text { fuerza alcohólica y } \\
45 \% \text { de extracto seco } \\
\text { a } \$ 0,08 / \text { lt.) }\end{array}$ & $\begin{array}{l}\text { específicos (cerveza } \\
\text { embotellada } \$ 0,12 / \\
\text { botella y vinos } \\
\text { comunes de no más } \\
\text { de } 15 \text { grados de } \\
\text { fuerza alcohólica y } \\
45 \% \text { de extracto seco } \\
\text { a } \$ 0,08 / \text { lt.) }\end{array}$ & $\begin{array}{l}\text { específicos (cerveza } \\
\text { embotellada } \$ 0,12 / \\
\text { botella y vinos } \\
\text { comunes de no más } \\
\text { de } 15 \text { grados de } \\
\text { fuerza alcohólica y } \\
45 \% \text { de extracto seco } \\
\text { a } \$ 0,08 / 1 \mathrm{lt} \text {.) }\end{array}$ \\
\hline $\begin{array}{l}\text { Mercería y artículos } \\
\text { de bazar y de fantasía }\end{array}$ & $\begin{array}{l}25 \% \text { y específicos } \\
\text { (papel de colores } \\
\$ 0,12 / \mathrm{kg} \text {. y papel } \\
\text { blanco para diarios } \\
\$ 0,03 / \mathrm{kg} . \text { ) }\end{array}$ & $25 \%$ y $40 \%$ & $\begin{array}{l}5 \%, 25 \%, 35 \% \text { y } \\
40 \% \text { y específicos } \\
\text { (papel de colores } \\
\$ 0,10 / \mathrm{kg} . \text { y papel } \\
\text { blanco para diarios } \\
\$ 0,025 / \mathrm{kg} . \text { ) }\end{array}$ \\
\hline $\begin{array}{l}\text { Lamparería y } \\
\text { artículos de } \\
\text { iluminación }\end{array}$ & $\begin{array}{l}5 \%, 25 \% \text { y } \\
\text { específicos (fósforos } \\
\text { de palo sueltos a } \\
\$ 0,4 / \mathrm{kg} \text {., fósforos de } \\
\text { cera sueltos a } \$ 1,6 / \\
\mathrm{kg} \text { ) }\end{array}$ & $\begin{array}{l}5 \%, 25 \% \text { y } \\
\text { específicos (fósforos } \\
\text { de palo sueltos a } \\
\$ 0,4 / \mathrm{kg} ., \text { fósforos de } \\
\text { cera sueltos a } \$ 1,6 / \\
\mathrm{kg} \text { ) }\end{array}$ & $\begin{array}{l}5 \%, 10 \%, 25 \% \text { y } \\
\text { específicos (fósforos } \\
\text { de palo sueltos a } \\
\$ 0,4 / \mathrm{kg} \text {., fósforos de } \\
\text { cera sueltos a } \$ 1,6 / \\
\mathrm{kg} \text { ) }\end{array}$ \\
\hline Cerámica y cristales & $25 \%$ & $25 \%$ & $25 \%$ \\
\hline $\begin{array}{l}\text { Droguería, productos } \\
\text { químicos, útiles y } \\
\text { accesorios }\end{array}$ & $\begin{array}{l}\%, 10 \%, 40 \% \text { y } \\
\text { específicos (aceites } \\
\text { vegetales } \$ 0,1 / 1 \mathrm{t} .)\end{array}$ & $\begin{array}{l}\%, 10 \%, 40 \% \text { y } \\
\text { específicos (aceites } \\
\text { vegetales } \$ 0,1 / 1 \mathrm{t} . \text {.) }\end{array}$ & $\begin{array}{l}5 \%, 10 \%, 25 \% \text { y } \\
\text { específicos (aceites } \\
\text { vegetales } \$ 0,1 / \mathrm{kg} .)\end{array}$ \\
\hline Tabacos & $\begin{array}{l}\text { específicos (cigarros } \\
\text { habanos } \$ 2,25 / \mathrm{kg} . \\
\text { cigarros no habanos } \\
\$ 0,75 / \mathrm{kg} . \text {, tabaco } \\
\text { habano en hojas } \\
\$ 0,7 / \mathrm{kg} . \text {, tabaco } \\
\text { habano picadura } \\
\$ 0,7 / \mathrm{kg} . \text {, tabaco en } \\
\text { hoja o picadura otras } \\
\text { procedencias } \$ 0,22 / \\
\mathrm{kg} . \text { tabaco paraguayo } \\
\$ 0,12 / \mathrm{kg} . \text { cigarrillos } \\
\$ 1 / \mathrm{kg} . \text {.) }\end{array}$ & $\begin{array}{l}\text { específicos (cigarros } \\
\text { habanos } \$ 2,25 / \mathrm{kg} . \\
\text { cigarros no habanos } \\
\$ 0,75 / \mathrm{kg} . \text {, tabaco } \\
\text { habano en hojas } \\
\$ 0,7 / \mathrm{kg} \text {., tabaco } \\
\text { habano picadura } \\
\$ 0,7 / \mathrm{kg} . \text { tabaco en } \\
\text { hoja o picadura otras } \\
\text { procedencias } \$ 0,22 / \\
\mathrm{kg} . \text { tabaco paraguayo } \\
\$ 0,12 / \mathrm{kg} \text {., cigarrillos } \\
\$ 1 / \mathrm{kg} .)\end{array}$ & $\begin{array}{l}\text { específicos (cigarros } \\
\text { habanos } \$ 2,25 / \mathrm{kg} . \\
\text { cigarros no habanos } \\
\$ 0,75 / \mathrm{kg} . \text { tabaco } \\
\text { habano en hojas } \\
\$ 0,7 / \mathrm{kg} . \text { tabaco } \\
\text { habano picadura } \\
\$ 0,7 / \mathrm{kg} ., \text { tabaco en } \\
\text { hoja o picadura otras } \\
\text { procedencias } \$ 0,22 / \\
\text { kg., tabaco paraguayo } \\
\$ 0,12 / \mathrm{kg} \text {., cigarrillos } \\
\$ 1 / \mathrm{kg} .)\end{array}$ \\
\hline
\end{tabular}


(continuación) Análisis CR-1899

\begin{tabular}{|c|c|c|c|}
\hline $\begin{array}{l}\text { Categoría de } \\
\text { productos }\end{array}$ & $\begin{array}{l}\text { Arancel vigente } \\
\text { Ley de Aduana } \\
1899\end{array}$ & $\begin{array}{l}\text { Arancel sugerido } \\
\text { por CR-1899 }\end{array}$ & $\begin{array}{l}\text { Arancel votado en } \\
\text { Ley de Aduana de } \\
\mathbf{1 9 0 0}\end{array}$ \\
\hline Varios & $\begin{array}{l}5 \%, 25 \%, 40 \% \text { y } \\
\text { específicos (cuellos } \\
\text { de algodón } \$ 1,25 / \\
\text { doc. y puños de } \\
\text { algodón } \$ 2 / \text { docena) }\end{array}$ & $\begin{array}{l}5 \%, 25 \%, 40 \% \text { y } \\
\text { específicos (cuellos } \\
\text { de algodón } \$ 1,25 / \\
\text { doc. y puños de } \\
\text { algodón } \$ 2 / \text { docena) }\end{array}$ & $\begin{array}{l}5 \%, 25 \%, 40 \% \text { y } \\
\text { específicos (cuellos } \\
\text { de algodón } \$ 1,25 / \\
\text { doc. y puños de } \\
\text { algodón } \$ 2 / \text { docena) }\end{array}$ \\
\hline Materias primas & $\begin{array}{l}\text { libres, } 2,5 \%, 5 \% \text {, } \\
10 \%, 15 \%\end{array}$ & $\begin{array}{l}5 \%, 10 \%, 15 \% \text { y } \\
25 \%\end{array}$ & $\begin{array}{l}5 \%, 10 \%, 15 \% y \\
25 \%\end{array}$ \\
\hline Artículos libres & $\begin{array}{l}\text { alcornoque, animales, } \\
\text { arena, buques, caña } \\
\text { de azúcar, carbón, } \\
\text { cascos, coke, material } \\
\text { ferroviario, dinamita } \\
\text { para minas, envases } \\
\text { para carnes, frutas } \\
\text { frescas, harina } \\
\text { de trigo o maíz, } \\
\text { acero viejo, leña, } \\
\text { libros, locomotoras, } \\
\text { material para } \\
\text { salubridad, máquinas } \\
\text { agrícolas, material de } \\
\text { inmigrantes, moneda } \\
\text { metálica, nafta, } \\
\text { objetos para culto, } \\
\text { oro, plata, pescado } \\
\text { fresco, plantas vivas, } \\
\text { semillas, trigo y } \\
\text { útiles escolares }\end{array}$ & No modifica & No modifica \\
\hline Exportables & $\begin{array}{l}\text { libres, } 4 \% \text { y } \\
\text { específico (hierro y } \\
\text { acero viejos a } \$ 5 / \text { tn.) }\end{array}$ & $\begin{array}{l}\text { libres, } 4 \% \text { y } \\
\text { específico (hierro y } \\
\text { acero viejos a } \$ 5 / \text { tn.) }\end{array}$ & $\begin{array}{l}\text { libres, } 4 \% \text { y } \\
\text { específico (hierro y } \\
\text { acero viejos a } \$ 5 / \text { tn.) }\end{array}$ \\
\hline
\end{tabular}

Fuente: Elaboración propia a partir de informes de las Comisiones Revisoras y de leyes aduaneras. 
Tabla 3: Análisis CR-1907 (aranceles vigentes, propuesta y ley posterior)

\begin{tabular}{|c|c|c|c|}
\hline $\begin{array}{l}\text { Categoría de } \\
\text { productos }\end{array}$ & $\begin{array}{l}\text { Arancel vigente Ley de Aduana } \\
1905\end{array}$ & $\begin{array}{l}\text { Arancel } \\
\text { sugerido por } \\
\text { CR-1907 }\end{array}$ & $\begin{array}{l}\text { Ley de } \\
\text { Aduanas } \\
\text { para } 1908\end{array}$ \\
\hline Cueros y pieles & $25 \%, 40 \%$ & $25 \%$ y $40 \%$ & \multirow{15}{*}{$\begin{array}{l}\text { No tuvo } \\
\text { efectos, } \\
\text { ya que se } \\
\text { continuó } \\
\text { replicando } \\
\text { la ley de } \\
\text { Aduanas de } \\
1905 .\end{array}$} \\
\hline Talabartería & $25 \%$ y $50 \%$ & $25 \%$ y $50 \%$ & \\
\hline Zapatería & $25 \%$ y $40 \%$ & $25 \%$ y $45 \%$ & \\
\hline $\begin{array}{l}\text { Confecciones y } \\
\text { ropa hecha }\end{array}$ & $25 \%, 35 \%, 40 \%$ & $\begin{array}{l}25 \%, 30 \% \text { y } \\
45 \%\end{array}$ & \\
\hline Tejidos & $\begin{array}{l}5 \%, 10 \%, 15 \%, 20 \%, 25 \%, 30 \%, 35 \% \text {, } \\
40 \% \text { y específico (fieltros adherentes } \\
\text { para sombreros de hombre } \$ 0,30 / \mathrm{kg} . \text { ) }\end{array}$ & $\begin{array}{l}5 \%, 10 \%, 20 \% \\
25 \%, 30 \%, 45 \% \\
\text { у } 60 \%\end{array}$ & \\
\hline $\begin{array}{l}\text { Artículos e } \\
\text { instrumentos de } \\
\text { música }\end{array}$ & $25 \%$ & $25 \%$ & \\
\hline Armería & $25 \%$ y $50 \%$ & $25 \%$ y $50 \%$ & \\
\hline $\begin{array}{l}\text { Alhajas y } \\
\text { relojes }\end{array}$ & $5 \%, 25 \%$ & $5 \%$ y $25 \%$ & \\
\hline Sombrerería & $\begin{array}{l}25 \%, 40 \% \text { y específicos }(\$ 0,35 \text { de lana y } \\
\$ 2 \text { copa alta) }\end{array}$ & $25 \%$ у $60 \%$ & \\
\hline Mueblería & $25 \%, 40 \%$ & $\begin{array}{l}25 \%, 30 \% y \\
45 \%\end{array}$ & \\
\hline $\begin{array}{l}\text { Ferretería y } \\
\text { artículos navales }\end{array}$ & $5 \%, 10 \%, 20 \%, 25 \%, 35 \%, 40 \%$ & $\begin{array}{l}5 \%, 10 \%, 25 \% \\
\text { y } 30 \%\end{array}$ & \\
\hline Comestibles & $\begin{array}{l}10 \%, 25 \% \text {, específicos (arroz } \$ 0,02 / \mathrm{kg} \text {., } \\
\text { azúcar refinada } \$ 0,09 / \mathrm{kg} \text {., café en grano } \\
\$ 0,03 / \mathrm{kg} . \text {, té } \$ 0,2 / \mathrm{kg} . \text { y yerba general } \\
\$ 0,04 / \mathrm{kg} \text {.) y libres (caña de azúcar, } \\
\text { harina de trigo y maíz, trigo) }\end{array}$ & $\begin{array}{l}\text { libres, } 10 \%, \\
25 \%, 45 \%, 50 \% \\
\text { y } 80 \%\end{array}$ & \\
\hline Bebidas & $\begin{array}{l}\text { específicos (cerveza embotellada } \$ 0,10 / \\
\text { botella y vinos comunes de no más de } \\
15 \text { grados de fuerza alcohólica y } 35 \% \text { de } \\
\text { extracto seco a } \$ 0,08 / 1 \mathrm{t} \text {.) }\end{array}$ & $\begin{array}{l}25 \%, 50 \% \text { y } \\
80 \%\end{array}$ & \\
\hline $\begin{array}{l}\text { Mercería y } \\
\text { artículos de } \\
\text { bazar y de } \\
\text { fantasía }\end{array}$ & $\begin{array}{l}5 \%, 25 \%, 35 \%, 40 \% \text { y específicos (papel } \\
\text { de colores } \$ 0,08 / \mathrm{kg} \text {. y papel blanco para } \\
\text { diarios } \$ 0,02 / \mathrm{kg} . \text { ) }\end{array}$ & $\begin{array}{l}5 \%, 25 \%, 30 \% \\
45 \%, 50 \%\end{array}$ & \\
\hline $\begin{array}{l}\text { Lamparería y } \\
\text { artículos de } \\
\text { iluminación }\end{array}$ & $\begin{array}{l}25 \%, 35 \% \text { y específicos (fósforos de } \\
\text { palo sueltos a } \$ 0,4 / \mathrm{kg} \text {., fósforos de cera } \\
\text { sueltos a } \$ 1,6 / \mathrm{kg} \text { ) }\end{array}$ & $\begin{array}{l}10 \%, 25 \% \\
30 \%, 50 \%\end{array}$ & \\
\hline
\end{tabular}


(continuación) Análisis CR-1907

\begin{tabular}{|c|c|c|c|}
\hline $\begin{array}{l}\text { Categoría de } \\
\text { productos }\end{array}$ & $\begin{array}{l}\text { Arancel vigente Ley de Aduana } \\
1905\end{array}$ & $\begin{array}{l}\text { Arancel } \\
\text { sugerido por } \\
\text { CR-1907 }\end{array}$ & $\begin{array}{l}\text { Ley de } \\
\text { Aduanas } \\
\text { para } 1908\end{array}$ \\
\hline $\begin{array}{l}\text { Cerámica y } \\
\text { cristales }\end{array}$ & $25 \%$ & $25 \%$ & \multirow{7}{*}{$\begin{array}{c}\text { No tuvo } \\
\text { efectos, } \\
\text { ya que se } \\
\text { continuó } \\
\text { replicando } \\
\text { la ley de } \\
\text { Aduanas de } \\
1905 .\end{array}$} \\
\hline $\begin{array}{l}\text { Droguería, } \\
\text { productos } \\
\text { químicos, útiles } \\
\text { y accesorios }\end{array}$ & $\begin{array}{l}5 \%, 10 \%, 25 \%, 50 \% \text { y específicos } \\
\text { (aceites vegetales } \$ 0,1 / \mathrm{kg} . \text { ) }\end{array}$ & $\begin{array}{l}10 \%, 20 \%, \\
25 \%, 45 \% \text { y } \\
50 \%\end{array}$ & \\
\hline Tabacos & $\begin{array}{l}\text { específicos (cigarros habanos } \$ 2,25 / \mathrm{kg} \text {., } \\
\text { cigarros no habanos } \$ 0,75 / \mathrm{kg} \text {., tabaco } \\
\text { habano en hojas } \$ 0,7 / \mathrm{kg} \text {., tabaco habano } \\
\text { picadura } \$ 0,7 / \mathrm{kg} \text {., tabaco en hoja o } \\
\text { picadura otras procedencias } \$ 0,22 / \mathrm{kg} \text {., } \\
\text { tabaco paraguayo } \$ 0,12 / \mathrm{kg} \text {., cigarrillos } \\
\$ 1 / \mathrm{kg} \text {.) }\end{array}$ & $60 \%$ & \\
\hline \multicolumn{3}{|l|}{ Varios } & \\
\hline Materias primas & $5 \%, 10 \%, 15 \%$ y libres & $\begin{array}{l}5 \%, 10 \%, 20 \% \\
\text { y libres }\end{array}$ & \\
\hline Artículos libres & $\begin{array}{l}\text { alcornoque, animales, arena, buques, } \\
\text { caña de azúcar, carbón, cascos, coke, } \\
\text { material ferroviario, dinamita para minas, } \\
\text { envases para carnes, frutas frescas, } \\
\text { harina de trigo o maíz, acero viejo, } \\
\text { leña, libros, locomotoras, material para } \\
\text { salubridad, máquinas agrícolas, material } \\
\text { de inmigrantes, moneda metálica, nafta, } \\
\text { objetos para culto, oro, plata, pescado } \\
\text { fresco, plantas vivas, semillas, trigo y } \\
\text { útiles escolares }\end{array}$ & $\begin{array}{l}\text { Suprimir } \\
\text { maquinaria } \\
\text { agraria, } \\
\text { alcornoque, } \\
\text { arena, dinamita } \\
\text { para minas, } \\
\text { envases para } \\
\text { carnes, acero } \\
\text { viejo, nafta, } \\
\text { libros }\end{array}$ & \\
\hline Exportables & libres y específico (hierro viejo a $\$ 5 /$ tn.) & libres & \\
\hline
\end{tabular}

Fuente: Elaboración propia a partir de informes de las Comisiones Revisoras y de leyes aduaneras. 